Comida PP, Ross P-S, Dürig T, White JDL, Lefebvre N (2022) Standardized analysis of juvenile pyroclasts in comparative studies of primary magma fragmentation; 2. Choice of size fractions and method optimization. Bull Volc. 84 article 14, DOI/10.1007/s00445-021-01517-5

\title{
Standardized analysis of juvenile pyroclasts in comparative studies of primary magma fragmentation; 2 . Choice of size fraction and method optimization for particle cross-sections
}

\author{
Pier Paolo Comida ${ }^{1, *}$, Pierre-Simon Ross ${ }^{1}$, Tobias Dürig ${ }^{2}$, James D.L. White ${ }^{3}$, Nathalie Lefebvre ${ }^{4}$ \\ 1. Institut national de la recherche scientifique, 490 rue de la Couronne, Québec (Qc), G1K 9A9, Canada, \\ pier_paolo.comida@inrs.ca, pierre-simon.ross@inrs.ca \\ 2. Institute of Earth Sciences, University of Iceland, Sturlugata 7, 101 Reykjavík, Iceland \\ tobi@hi.is \\ 3. Department of Geology, University of Otago, 360 Leith Street, Dunedin 9016, New Zealand, james.white@otago.ac.nz \\ 4. ETH Zurich, Institute of Geochemistry and Petrology, Clausiusstrasse 25, 8092 Zurich, Switzerland \\ * Corresponding author, pier_paolo.comida@inrs.ca
}

\begin{abstract}
The morphological and textural features of juvenile pyroclasts record crucial details on magma conditions at the time of fragmentation. Their study is therefore essential to better understand the dynamics of explosive eruptions. Unfortunately, the absence of a standardized protocol of investigation hinders data reproducibility and comparison among different laboratories. Here we focus on morphometric parameters, 2D crystallinity and 2D vesicularity resulting from cross-section analysis of juvenile particles using backscattered electron imaging, and address the following questions: i) how to prepare polished epoxy grain mounts; ii) which pixel density to be used; iii) how to facilitate image preparation and image analysis; iv) which sample size is necessary to obtain statistically robust results; $v$ ) what is the optimum size fraction for analysis. We test juvenile particles in grain size bins ranging from $2-1 \mathrm{~mm}(-1$ to $0 \phi)$ to $88-63 \mu \mathrm{m}$ $(+3.5$ to $+4 \phi)$, using samples from the 1977 Ukinrek eruption. We find that the required resolution ranges from 75000 to 10000 pixels per particle, depending on the size fraction, higher than previously postulated. In the same size ranges, less than 50 grains per size fraction and sample are needed to get robust averages. Based on theoretical, empirical and practical considerations, we propose $0.71-0.5 \mathrm{~mm}(+0.5$ to $+1 \phi)$ as the optimum size fraction to be analyzed as particle cross-sections in standardized comparative studies of magma fragmentation. We provide a detailed guide for preparing polished epoxy grain mounts and introduce a software package (PASTA) for semi-automated image preparation, image processing and measurement of morphological and textural parameters.
\end{abstract}

\begin{abstract}
Introduction
Juvenile particles in pyroclastic deposits preserve key information on fragmentation mechanisms (e.g., Dellino and La Volpe 1996; Zimanowski et al. 1997; Cioni et al. 2014; Jordan et al. 2014; Rausch et al. 2015; Verolino et al. 2019; Dürig et al. 2020a, 2020b, 2020c) and on the state of magma at the time of fragmentation (e.g., Heiken 1972; Heiken and Wohletz 1985; Freundt and Rosi 1998; Lautze and Houghton 2007; Rust and Cashman 2011; Dürig and Zimanowski 2012; Liu et al. 2017). This knowledge is important for understanding eruptive processes, including those that produce hazardous activity (Dellino et al. 2012; Leibrandt and Le Pennec 2015; Avery et al. 2017). Specific morphological features, particle surface features and internal textures (related to crystals and bubbles) can be measured, and the ash range is typically targeted (e.g.,
\end{abstract}

Dellino and La Volpe 1996; Büttner et al. 1999; Liu et al. 2017). Yet, despite decades of research on juvenile particles, a standard methodology of analysis does not yet exist for comparative studies. Differences between laboratories include the choice of imaging device (scanning electron microscope (SEM), micro-CT, automated particle imager, other microscope or device), which particle size to use, whether to use silhouettes or particle cross-sections, which morphometric parameters are best, what statistical methods to perform, etc. (e.g., Dellino and La Volpe 1996; Büttner et al. 2002; Leibrandt and Le Pennec 2015; Liu et al. 2015; Dürig et al. 2018; Dürig et al. 2021). Also, particle shapes have often been measured independently of particle surface features and internal textures (Cioni et al. 1992; Rausch et al. 2015; Liu et al. 2017). 
The lack of a standardized methodology to study juvenile particles means that data from different laboratories and different volcanoes cannot be integrated and directly compared. We therefore propose, in two papers, a standardized methodology for comparative studies, which can be discussed and refined during an international workshop. In the first paper, Ross et al. (2022) give an overview of the whole workflow, which includes standard steps and recommended steps (Figs. 1 and 2 in Ross et al. 2022). Initial standard steps include fieldwork, sampling, geochemistry and sieving (Fig. 1). Further standard steps are tailored for each recommended cleaned size fraction, as follows: i) for the $0.71-0.5 \mathrm{~mm}$ ash size fraction $(+0.5$ to $+1 \phi$ ) (see White and Houghton 2006 for definition of grain size terms), basic componentry, juvenile selection, preparation of polished epoxy grain mounts (PEGMs), imaging of the particle cross-sections with an SEM and measurements of morphometric parameters, 2D vesicularity, and 2D crystallinity; ii) for the $88-63 \mu \mathrm{m}$ $(+3.5$ to $+4 \phi)$ grains, dual mounting (both carbon tape and polished epoxy) of the bulk size fraction, imaging twice at the SEM, basic componentry on particle cross-sections, searching for interactive particles, and measurement of morphometric parameters on juvenile particle silhouettes.

This paper focuses on particle cross-sections imaged with an SEM and completes the standardized methodology proposal by providing information on the following topics not covered in detail by Ross et al. (2022) (Fig. 1):

(1) The method for preparing a standard PEGM;

(2) The SEM magnification and image resolution needed to obtain enough pixels per particle, to ensure stable average values of morphometric parameters, 2D crystallinity and 2D vesicularity;

(3) The minimum number of particles required to obtain statistically robust averages for morphometric parameters, vesicularity and crystallinity;

(4) The process for automating image preparation and image analysis as much as possible, and which manual steps are still needed to obtain good results;

(5) The rationale for choosing the $0.71-0.5 \mathrm{~mm}(+0.5$ to $+1 \phi$ ) size fraction as the best compromise for determining both morphometric parameters and internal textures.

In order to assess the best size fraction to use for juvenile particle cross-sections in fragmentation studies, we measured morphometric parameters and internal features on size fractions from $2-1 \mathrm{~mm}(-1$ to $0 \phi)$ to $88-63 \mu \mathrm{m}(+3.5$ to $+4 \phi)$, on natural basaltic samples, derived from both magmatic and phreatomagmatic fragmentation. As detailed in the manuscript, the investigation ultimately led to the choice of the $0.71-0.5 \mathrm{~mm}(+0.5$ to $+1 \phi)$ as one of the three size fractions proposed in the standardized methodology (Ross et al. 2022). Image preparation and analysis has many steps, and details have often been lacking in previous publications. We explain our methods in detail and present semi-automated scripts to save the user as much time as possible.

\section{Background}

Imaging methods and strategies

The study of shapes and textures of juvenile pyroclasts is carried out on particle images. These images can be obtained with particle sizing and imaging devices, with a SEM, or with micro-CT methods (Schipper et al. 2013; Vonlanthen et al. 2015; Dioguardi et al. 2017; Mele and Dioguardi 2018; Mele et al. 2018). Unfortunately, results based on different imaging systems may not be comparable (Ross et al. 2022 and references therein). The present contribution focuses on SEMBSE (backscattered electron) imaging of particle crosssections, which allow both morphometric parameters and internal textures to be assessed from the same images.

The resolution and magnification of a SEM-BSE image are critical parameters to obtain reliable and comparable measurements. Previous workers have recommended 750 to 5000 pixels per particle for shape measurements, mainly in the 125-63 $\mu \mathrm{m}(+3$ to $+4 \phi)$ size fraction (Dellino and La Volpe 1996; Dürig et al. 2012; Liu et al. 2015). The larger value has also been considered optimum for coarse ash grains (Mele et al. 2011). We show below that this range is probably insufficient for obtaining stable values for the combination of crystallinity, vesicularity, and morphometric parameters.

Two imaging strategies are possible when internal textures are important: (1) collect images at a high enough resolution or (2) progressively increase the magnification in a nesting strategy (Shea et al. 2010b). In this study, we determine the imaging settings that are sufficient to quantify both the shape and internal texture from one image, preferably containing multiple particles, to minimize total SEM time.

\section{Sample preparation}

To acquire SEM-BSE images of particle cross-sections, the grains are usually embedded in epoxy resin, ground down to expose the grain interiors. This ground epoxy 'briquette' can be mounted to a glass slide, thinned and polished to make a polished thin section, or it can simply be polished to produce the grain mount (PEGM). Published papers rarely describe sample preparation in detail, but there are several steps in the manufacture of PEGMs/polished thin sections, and these play a critical role in obtaining a 2D cross-section representative of the whole particle. Particularly important are the orientation of a grain relative to the polishing surface, and the extent of grinding/polishing which controls the area size of the grain exposed. Moreover, embedding under pressure and/or vacuum may be necessary for vesicular grains with fine vesicles, as epoxy-filled vesicles will have a better chance to be preserved during grinding and polishing.

\section{Number of particles to image}

Another important parameter to be assessed is the number of grains needed to obtain statistically robust results for morphometric and textural measurements, for a given size fraction in a sample. Previous studies have used particle numbers spanning several orders of magnitude (e.g., Durant et al. 2009: 100000 particles; Cioni et al. 2008: 30 particles), as 
well as different size fractions and image acquisition systems. For example:

- Liu et al. (2015) suggested 1000-2000 grains for the $125-63 \mu \mathrm{m}(+3$ to $+4 \phi)$ fraction as the optimum number to achieve stable morphometric parameter averages. Their test was based on particle cross-sections imaged with an SEM.

- Leibrandt and Le Pennec (2015) recommended 150 and 2000 grains for the $1.0-0.5 \mathrm{~mm}$ ( 0 to $+1 \phi)$ and $125-63 \mu \mathrm{m}(+3$ to $+4 \phi)$ size fractions, respectively, using an automated optical particle analyzer (i.e., a modified version of an optical microscope) to measure morphometric parameters on silhouettes.

- Dürig et al. (2018) suggested a minimum number of 50 grains for obtaining statistically robust averages in morphometric analyses of particle silhouettes, imaged with an SEM.

- Mele and Dioguardi (2018) performed 3D X-ray microtomography on 30 fallout pyroclasts spanning a size range between $16-8 \mathrm{~mm}$ ( -4 to $3 \phi)$ and $63-31 \mu \mathrm{m}(+4$ to $+5 \phi)$, belonging to three different eruptions of Campi Flegrei (Italy). The particles were morphometrically parameterized by using 3-dimensional morphometric parameters, such as fractal dimension, sphericity or (3D) shape factor (Dioguardi et al. 2017).

\section{Image preparation and analysis}

The analysis of particle images has benefited from the advancement in computer technology over the last decades. Liu et al. (2015) provided a macro code for the image processing software ImageJ (Schneider et al. 2012) that allows measurement of a set of morphometric parameters on 2D particle cross-sections. The required input is a stitched binary image containing multiple particles.

Another macro code for the same software package was developed by Hornby (2018), which measures both shapes and internal textures. This technique relies on false color QEMSCAN® multi-particle images, manually converted to one binary image per feature (e.g., vesicles, crystal phase 1 , crystal phase 2 , glass, etc.).

Dürig et al. (2018) introduced PARTISAN, a script for Matlab $^{\odot}$ which measures, in its newest version (Dürig and Bowman 2021), 23 non-dimensional morphometric parameters, based on five different morphometric systems by Dellino and La Volpe (1996), Cioni et al. (2014), Leibrandt and Le Pennec (2015), Liu et al. (2015) and Schmith et al. (2017). The required input consists of binarized SEM images acquired from particle silhouettes, with each image containing only one particle.

In all three cases cited above, the codes require "ready to use" binary images of single or multiple particles. Obtaining these images involves either (i) manual stitching and thresholding of several SEM images (for the Liu et al. code); (ii) an expensive and proprietary data acquisition system and some manual processing (for the Hornby code); or (iii) manual separation and generation of single particle images (for the Dürig et al. code). None of the scripts available in the literature enables a quick, automated and inexpensive generation of single particle binary images, neither do they produce single particle image files showing a ready-toquantify internal texture such as crystallinity or vesicularity.

\section{Methods}

\section{Origin of tested material}

The natural juvenile pyroclasts used here come from the Ukinrek Maars (Alaska), which erupted in 1977 and emitted alkaline basalt (Kienle et al. 1980). The whole event lasted for about 11 days and formed two maars (west and east, Kienle et al. 1980) preceded by fissural activity southeast of the west maar (Ort et al. 2018). We selected two end-member samples for this study: a phreatomagmatic one and a Strombolian one. Both samples were chosen from very proximal units, to minimize transport effects on particle morphology. They were taken from deposits representing the beginning of an eruptive episode, to avoid recycled pyroclasts.

The Strombolian sample comes from a juvenile-rich fallout deposit linked to the initial fissural activity (F1 unit, Ort et al. 2018). Juvenile ash is brown to black scoria, characterized by irregular shapes (Fig. 2a). Following the classification of Houghton and Wilson (1989), juvenile clasts are incipiently to moderately vesicular (5-60\%). Vesicle sizes range from about $10 \mu \mathrm{m}$ to over $1 \mathrm{~mm}$ across (Fig. 2b), and vesicles are often connected in 3D. Crystals (including phenocrysts of all sizes and microlites) are moderately to highly abundant (typically $\sim 40-80 \%$ in coarse ash-sized juvenile clasts) (Fig. 2b). Olivines are the largest phenocrysts $(250 \mu \mathrm{m}-1.5 \mathrm{~mm})$, have euhedral to anhedral shapes, and are commonly characterized by edge resorption (Fig. 2b). Inclusions of glass and oxides are common within the olivines. Magnetite crystals are euhedral, ranging from about 3 to $50 \mu \mathrm{m}$ across. Anorthite-rich plagioclase microphenocrysts are the second largest population. They are euhedral to subhedral and $15-650 \mu \mathrm{m}$ across, embedded in a sideromelane-bearing groundmass.

The phreatomagmatic sample comes from the lithic-rich PDC unit at the base of the East Maar ejecta ring (EM1 unit of Ort et al. 2018). Juvenile clasts have generally sub-equant shapes (Fig. 2c). Vesicles are isolated, subround to amoeboid (5$600 \mu \mathrm{m})$, and the coarse ash-sized juvenile clasts are poorly to highly vesicular ( 30-60\%). Crystallinity is high ( $>50 \%)$, with similar minerals as in the Strombolian sample, and the groundmass is tachylitic (Fig. 2d).

Overview of the standardized protocol and of the present study In the companion paper, Ross et al. (2022) present a standardized protocol for the analysis of juvenile pyroclasts for comparative studies of primary magma fragmentation, and their standard steps are shown in Fig. 1. Two main size fractions are included in the flowchart: $0.71-0.5 \mathrm{~mm}(+0.5$ to $+1 \phi)$ and $88-63 \mu \mathrm{m}(+3.5$ to $+4 \phi)$. Juvenile particles from the $0.71-0.5 \mathrm{~mm}(+0.5$ to $+1 \phi)$ fraction are made into a PEGM, from which morphometric parameters and internal textures can be determined for each grain, based on particle cross-sections. The bulk $88-63 \mu \mathrm{m}(+3.5$ to $+4 \phi)$ fraction is prepared as a 
carbon tape grain mount, imaged, and then converted to a PEGM and imaged again. This allows determination of basic componentry, morphometric parameters, and surface features for juvenile grains. To reach this simplified protocol, we first needed to determine which size fraction is optimal for the joint measurement of morphometric and textural parameters. Therefore, for each of our two samples we prepared PEGMs for five size fractions between 2$1 \mathrm{~mm}(-1$ to $0 \phi)$ and $88-63 \mu \mathrm{m}(+3.5$ to $+4 \phi)$, and then measured morphometric parameters and internal textures.

This size range includes the most popular size fractions considered in the literature for fragmentation studies (Dellino and La Volpe 1996; Büttner et al. 1999; Cioni et al. 2014; Jordan et al. 2014; Leibrandt and Le Pennec 2015; Liu et al. 2015 and references therein). The particles between $2-1 \mathrm{~mm}(-1$ to $0 \phi)$ and $88-63 \mu \mathrm{m}(+3.5$ to $+4 \phi)$ should also be small enough to have cooled very rapidly after fragmentation, hence preserving particle shapes related to fragmentation, and crystals and bubbles representing the state of magma at the time of fragmentation (Porritt et al. 2012; D’Oriano et al. 2014).

\section{Preparing the size fractions}

Sieving

The Ukinrek samples arrived pre-sieved into full $\phi$ fractions. The $2-1 \mathrm{~mm}(-1$ to $0 \phi), 0.5-0.25 \mathrm{~mm}(+1$ to $+2 \phi)$ and $0.25-0.125 \mathrm{~mm}(+2$ to $+3 \phi)$ fractions were utilized as is. We further narrowed the other two fractions using half $\phi$ sieves, yielding $0.71-0.5 \mathrm{~mm}(+0.5$ to $+1 \phi)$ and $88-$ $63 \mu \mathrm{m}(+3.5$ to $+4 \phi)$ fractions; unfortunately, other half-phi sieves were not available at INRS when this work was done. While comparing full $\phi$ and half $\phi$ fractions in the same study is not ideal, the dataset presented here still allows us to optimize the methodology in terms of image preparation and image analysis, pixel density for each grain, how many grains are needed, and what is the optimum size fraction for analysis. It also allows the demonstration that morphometric and textural parameters vary with grain size, as also shown by previous studies.

\section{Ultrasonic cleaning}

Particles from each size fraction were cleaned to remove adhering fine dust using an ultrasound bath at low intensity in cycles of 1 minute, for a total time of 3 minutes, using distilled water, and subsequently dried at $60^{\circ} \mathrm{C}$. These short cleaning cycles without the use of aggressive chemicals should minimize damage to the grains.

\section{Juvenile clast selection}

Natural samples contain a mixture of juvenile and lithic clasts, but only juvenile grains are to be used for magma fragmentation studies. In this study we selected hundreds of grains per sample and per size fraction, much more than were eventually needed, since one of the goals was to find out the minimum number grains needed to obtain statistically reliable averages. Manual hand picking of juvenile clasts under the binocular microscope was feasible for the size fractions $2-1 \mathrm{~mm}(-1$ to $0 \phi)$ to $0.5-0.25 \mathrm{~mm}(+1$ to $+2 \phi)$, requiring up to 20 minutes for every 50 juvenile grains selected. The $0.25-0.125 \mathrm{~mm}(+2$ to $+3 \phi)$ and $88-$
$63 \mu \mathrm{m}(+3.5$ to $+4 \phi)$ juvenile grains were also picked under the binocular microscope, but it was a time-consuming task, taking over 1 hour to yield about 100 juvenile grains. This was due to static electricity and physical limitations of the picking tools, which set a size limit for this kind of technique. Electrostatic charge effects often resulted in unwanted picking of lithics along with juvenile particles. Any remaining lithics were mounted along with the juveniles, only to be excluded later from the analysis, based on SEM imagery. Because of these practical problems with selecting very small juvenile fragments under the binocular microscope, and because it is impossible to be certain that each picked fragment is indeed juvenile, the standardized protocol calls for dual mounting of the bulk fraction for the $88-63 \mu \mathrm{m}(+3.5$ to $+4 \phi)$ particles (Ross et al. 2022).

\section{Polished epoxy grain mounts}

Imaging of particle cross-sections with an SEM necessitates PEGMs or polished thin sections. The PEGM manufacturing procedure developed as part of this study is summarized here and fully explained in Online Resource 1.

The juvenile grains were first placed on a very flat surface lined with double-sided tape (Fig. 3a), using different methods depending on the size fraction considered. For the coarser fractions $2-1 \mathrm{~mm}(-1$ to $0 \phi)$ to $0.5-0.25 \mathrm{~mm}(+1$ to $+2 \phi)$, the grains were mounted one by one on the tape (Fig. 3b). Particles were positioned to have their two longest axes parallel to the PEGM examination surface.

For the finer fractions $0.25-0.125 \mathrm{~mm}(+2$ to $+3 \phi)$ to $88-$ $63 \mu \mathrm{m}(+3.5$ to $+4 \phi)$, the material was first spread in a petri dish and then transferred to the mounting area using the "thumb method". A lightly moistened thumb was very gently pressed on a particle-rich portion of the petri dish, mimicking a fingerprint capture gesture. The movement was repeated on the exposed sticky surface of the mounting support until enough particles were transferred (Fig. 3c). In order to avoid contamination and prevent finger marks on the tape, the use of a latex/nitrile finger cot or glove is suggested. The cylindrical molding case was subsequently placed into position, then the blended epoxy mixture was poured into each mold and left to cure overnight within a vacuum chamber in order to ensure vesicle infilling by epoxy needed to avoid breakage during sectioning and imaging (Fig. 3d). The flat mounting surface was then detached.

Grinding and polishing of each mount aimed to expose the center of the smallest juvenile fragments in each size fraction. For example, for the $2-1 \mathrm{~mm}(-1$ to $0 \phi)$ fraction, we removed $0.5 \mathrm{~mm}$ of material, starting from the side on which the grains had been deposited. The grinding and polishing must be done very carefully to preserve the particle shapes in cross-section, as well as to minimize the formation of fractures and ablation of the mounted grains. Based on the equipment available at INRS (Institut national de la recherche scientifique, Canada), we settled on up to three grinding steps and two polishing steps, using a mix of abrasive paper and fine suspensions (Fig. 3e). A typical final product is shown in Fig. 3f, containing more grains than needed. 
Image acquisition

$\mathrm{Au} / \mathrm{Ir}$-Pd coated PEGMs were imaged at INRS using a Zeiss EVO 50 SEM in BSE mode. Images for each sample were acquired using an optimum working distance of 8.5 $\mathrm{mm}$, while magnification, image resolution and scan speed were adjusted relative to the size fraction, as explained in a later section. Further focus adjustments were unique to each PEGM because of the slightly different final thicknesses attained during polishing.

The time and number of images that were involved in scanning a whole PEGM increased for finer size fractions, because larger magnifications were necessary to capture finer details, ranging from $20-25$ images for $2-1 \mathrm{~mm} \mathrm{(-1} \mathrm{to}$ $0 \phi)$ and up to about 100 images for $88-63 \mu \mathrm{m}(+3.5$ to $+4 \phi)$ PEGMs. For the size fraction and the number of grains that we recommend for standardized comparative magma fragmentation studies, i.e. $0.71-0.5 \mathrm{~mm}(+0.5$ to $+1 \phi)$ and 50 juvenile grains (see discussion), about three images would be needed for each sample if all particles were grouped relatively closely together in the PEGM. In this case, the total imaging time would be about 10 minutes.

Brightness and contrast were set to provide a good separation in terms of greyscale intensity both between the resin and the particle edge, and between the particle groundmass, crystals and vesicles. This is an essential prerequisite for the image processing methodology developed in this work. All images from the same sample should ideally have comparable grey levels for the same features. For example, olivine crystals should always have a similar darkness. At the SEM, this can be better achieved by disabling the automatic adjustment of brightness and contrast when moving to the next acquisition area. Keeping the initial image open helps the operator ensure that subsequent images look similar. The groundmass often includes both microlites and glass, and it is sometimes difficult to distinguish them from a single particle or multiparticle image. A typical solution would be to zoom on the groundmass, but this is not a standard step in the figure 1 flowchart, as we are aiming for a bulk estimate of the crystallinity and therefore we are not using a nesting strategy. The image file format should be non-compressed (e.g., TIFF), to preserve original scan quality.

\section{Image preparation and measurements}

Image preparation and analysis was undertaken using a combination of semi-automated processing and manual refinement. An image preparation stage was done in a raster graphics editor (here Adobe Photoshop(C). This was followed by a processing and measurement stage in a scientific image analysis software (Fiji, Schindelin et al. 2012). Scripts which partially automate some of the steps were developed for both stages in order to save time and are available online as the PArticle Shapes \& Textures Analyzer ('PASTA') project (Comida and Ross 2021). The package includes detailed step-by-step user guides for both image preparation in Photoshop $(\mathrm{C}$ and image processing in Fiji, with a much shorter overview provided below.
Image preparation stage

SEM images have to be prepared (enhanced) before morphometric parameters and internal textures can be measured. Image preparation accomplishes the following: (1) making sure that the juvenile particle outlines are perfectly selected (Figs. 4a-4c); (2) keeping only juvenile fragments not touching the edges, eliminating lithic fragments and free crystals that escaped the juvenile selection process, and replacing the inter-particle background with a uniform color (Figs. 4d-4e); (3) for each multi-particle image, optionally improving the contrast between different internal features, such as crystals versus groundmass (Figs. 4f-4g); (4) for each juvenile fragment, blackening the vesicles and "repairing" obvious flaws, such as larger cracks (Figs. 4g-4h). Since certain kind of fractures might be important to recognize specific fragmentation-related processes such as thermal granulation (Colombier et al. 2019), the user could create a copy of the images to optionally study fractures, while using the other copy with repaired cracks to carry out standard textural measurements. The end products of the image preparation stage are multi-particle images containing only complete juvenile particles on a uniform background. These particles are characterized by well-defined edges and wellcontrasted internal features.

Processing and measurement stage

The Fiji script portion of PASTA allows the semi-automated processing and measurement of morphometric parameters, 2D crystallinity and 2D vesicularity of juvenile particles. Settings are optimized for BSE-SEM images of particle cross-sections, but morphometric parameters can also be measured on particle silhouettes. The code features a Graphical User Interface (GUI) with detailed instructions which results in only a small amount of straightforward user input. The script executes three main steps: (1) isolating single particles; (2) image processing; (3) measurements and saving the results (Fig. 3 in the PASTA user guide, Comida and Ross 2021).

Step 1. Isolating single particles is required for multi-particle images, since processing must be done on images containing one particle only. The script does this automatically for the entire batch of multi-particle images in the input folder.

Step 2. Image processing involves a series of operations that generate images directly suitable for measuring morphometric parameters and/or internal features. For morphometric parameters, a binary image is created, with a single black particle on a white background (Fig. 5a). For internal features (i.e., crystallinity and vesicularity), false-color segmented images are generated, with arbitrary greyscale intensities identifying the grey levels representing groundmass, crystals and vesicles, on a white background (Fig. 5b). During image segmentation, the user selects which internal features are to be extracted, what minimum size to use for each crystal or vesicle, and enters personalized labels (Fig. 7 upper half in the PASTA user guide, Comida and Ross 2021). Based on tests and in general agreement with previous studies (Shea et al. 2010b), we suggest a minimum (default) size of 4 pixels for vesicles and oxides, and 20 pixels for grey crystals. Such minimum values yield relatively clean refined images while accurately 
depicting internal features without underestimating their relative abundance.

For each selected feature (e.g., vesicles or plagioclase crystals) the minimum and maximum grey levels are identified using a representative area on a representative image (Fig. 8 in the PASTA user guide, Comida and Ross 2021). If a feature is not found on the current image (e.g., no vesicles present), the user can view other images. Once the optimum threshold values are inserted (Fig. 7 lower half in the PASTA user guide, Comida and Ross 2021), the final generation of the segmented images might occur either one particle at a time or as a batch for the whole stack of images, depending on user preference.

Step 3a: measurements. For shape parameters, PASTA uses a modified version of the Liu et al. (2015) code. PASTA batch-processes a stack of single particle binary images (e.g., Fig. 5a) for an entire sample. To obtain other morphometric parameters such as those of Dellino and La Volpe (1996), Cioni et al. (2014), Leibrandt and Le Pennec (2015), and Schmith et al. (2017), the PARTISAN script from Dürig et al. (2018) can be used on the single particle binary images extracted by PASTA. These morphometric parameters have been chosen for their capability to highlight different morphological characteristics, and to distinguish ductile from brittle fragmentation, as detailed in Ross et al. (2022).

$2 \mathrm{D}$ vesicularity and $2 \mathrm{D}$ crystallinity are calculated as the number of black (vesicle) and grey (crystal) pixels divided by the total surface area of the particle, respectively, on the false-color segmented images (e.g., Fig. 5b). In the future, we hope to provide the proportions of different crystal types as well, for each clast. The code could also be expanded to provide vesicle size distributions or crystal size distributions.

Step 3b: save results. Results may be saved as a csv file (by default) and/or exported as a Microsoft Excel(C file. The current output parameters include particle area, particle perimeter, area and perimeter of the convex hull bounding the particle, axial ratio, solidity, convexity, form factor, 2D vesicularity (both in pixels and \%), and 2D crystallinity (both in pixels and \%).

\section{Finding the best image resolution and magnification}

The number of pixels per particle (pixel density) needed to get stable values of morphometric parameters and internal textures is a function of both image resolution and SEM magnification. In our tests, we replicated the Liu et al. (2015) approach to determine the necessary pixel density but included 2D crystallinity and 2D vesicularity along with the morphometric parameters. The idea is to define a typical pixel number that stabilizes the values for each morphometric and textural parameter in a number of individual particles. The Strombolian sample from Ukinrek was used for these tests. For each size fraction, we selected four juvenile particles spanning the full range of crystallinity and vesicularity (i.e., minimum and maximum vesicularity; minimum and maximum crystallinity). Each particle image was initially acquired at a high magnification using the highest resolution available (i.e., $3072 * 2304$ pixels), then progressively downsampled in Photoshop $\subset$ by digitally decreasing the resolution by one-third intervals. The full image preparation and analysis described above was run on each resolution, for each endmember particle. A particular effort was made to avoid operator bias related to possible memory effect, alternating different particles after each manual refinement.

\section{Choice of parameters to find the optimum size fractions}

To quantify particle morphology, the companion paper (Ross et al. 2022) suggests two sets of morphometric parameters: i) three of the shape parameters suggested by Liu et al. (2015) and measured with PASTA: axial ratio, solidity and convexity; ii) the four morphometric parameters introduced as "IPA (image particle analysis) parameters" by Dellino and La Volpe (1996), i.e. circularity, rectangularity, compactness and elongation. The IPA parameters, measured here with PARTISAN (Dürig and Bowman 2021), were compared in pairs following Dürig et al. (2018), that is, for example, as the product of elongation times circularity and rectangularity times compactness. The first pair shows well the deviations from equant shapes, whereas the latter emphasizes morphological and textural roughness variations present in the particle outline. These morphometric parameters, along with 2D crystallinity and 2D vesicularity measurements obtained with PASTA, were used to assess critical aspects in the development of the methodology, as described in the next section. All measurements on the particles used in this study are available in Online Resource 2. All raw SEM images are available online from the Zenodo.org data repository (Comida et al. 2021).

\section{Results \\ Optimum pixel density for image analysis}

For each clast studied, the measured values of morphometric and textural parameters are dependent on pixel density (number of pixels per particle) (Figs. 6, 7). For example, 2D crystallinity values of individual grains typically increase with pixel density, stabilizing beyond 70000 pixels per particle for the $2-1 \mathrm{~mm}(-1$ to $0 \phi)$ size fraction, beyond 20000 pixels for the $0.71-0.5 \mathrm{~mm}(+0.5$ to $+1 \phi)$ fraction, and beyond 10000 pixels for the finer size fractions (Fig. 6, left). The most likely explanation is that small crystals are better resolved if more pixels are available, which is the equivalent of zooming in on the grain while keeping the image resolution constant. The trends for 2D vesicularity are partly similar, presumably because small vesicles are better resolved in better quality images, but typically, fewer pixels are needed to stabilize vesicularity than crystallinity in these samples (Fig. 6, right).

Convexity generally decreases when the pixel density increases (Fig. 7, left), because convexity depends on the inverse of perimeter, and the perimeter typically lengthens with better images (Liu et al. 2015). Convexity mostly stabilizes beyond 75000 pixels for the $2-1 \mathrm{~mm}(-1$ to $0 \phi)$ grains studied, beyond 20000 pixels for $0.71-0.5 \mathrm{~mm}(+0.5$ to $+1 \phi$ ), and beyond 10000 pixels for finer size fractions. Other morphometric parameters such as solidity (Fig. 7, right) and axial ratio (Online resource 3 ) stabilize at much lower pixel 
densities, beyond 40000 pixels for the $2-1 \mathrm{~mm} \mathrm{(-1} \mathrm{to} 0 \phi)$ fraction, beyond 10000 pixels for $0.71-0.5 \mathrm{~mm}(+0.5$ to $+1 \phi)$, and beyond 5000 pixels for finer size fractions. In summary, the pixel density needed to get stable values for both morphometric parameters and internal textures ranges from 75000 for the $2-1 \mathrm{~mm}(-1$ to $0 \phi)$ size fraction to 10000 in the $88-63 \mu \mathrm{m}(+3.5$ to $+4 \phi)$ size fraction (Table $1)$.

The role of scan speed in image acquisition

When discussing SEM imaging parameters, previous studies have focused on image resolution and magnification, without mentioning another crucial feature, scan speed. This represents the speed at which the electron beam swings over the examined area of a sample. Slower scan speed means longer imaging time but a finer definition of the details of the image (Fig. 8a). On the contrary, faster scan speed will downgrade the quality of the image, thereby compromising the accuracy of shape and, especially, textural measurements (Fig. 8b). The optimum scan speed provides sharp edge distinction between microlites and the glass in the groundmass, at the magnification and resolution used for the final image acquisition.

\section{Number of grains to measure}

The average values of measured morphometric and textural parameters, and their representativeness, are dependent on the number of grains studied in a sample. Average values will stabilize only when a sufficient number of grains have been analyzed, depending on the heterogeneity of the sample in terms of particle shapes and internal textures. In the Strombolian sample from Ukinrek, average vesicularity and crystallinity stabilize at about $20-25$ grains in the 2$1 \mathrm{~mm}(-1$ to $0 \phi)$ size fraction, whereas it takes only around 10 grains for solidity and convexity to do so (Fig. 9, top). In progressively finer size fractions, the number of grains generally increases to stabilize the textural parameters, reaching about 40 grains for the $88-63 \mu \mathrm{m}(+3.5$ to $+4 \phi)$ fraction (Fig. 9, bottom; Table 2). In the phreatomagmatic sample, the estimated number of grains needed to get stable averages for all parameters ranges from 20 grains at 2$1 \mathrm{~mm}(-1$ to $0 \phi)$ to 30 grains at $88-63 \mu \mathrm{m}(+3.5$ to $+4 \phi)$ (Fig. 10, Table 2).

Another way to estimate these minimum numbers of clasts is the " $5 \%$ variation" statistical method. For each parameter, grains are progressively added to the average until the effect of adding one more grain becomes less than $5 \%$ relative difference. In both samples, this method resulted in smaller cut-offs than the visual estimate (Table 2).

For reasons that will be explained below, for the standardized methodology (Ross et al. 2022), we ultimately selected the $0.71-0.5 \mathrm{~mm}(+0.5$ to $+1 \phi)$ size fraction for particle cross-sections. For this particular fraction, given the modest rejection rates discussed in the next section, a recommendation to analyze 50 grains (Fig. 1) seems safe given the much lower minimum numbers reported in Table 2. Again, this is the number of particles required to get stable averages, not to characterize different subpopulations. If these different subpopulations are of interest, a larger number of grains should be analyzed, but this is not a standard requirement in the figure 1 flowchart.

\section{Rejection rate}

We filtered out grains that were too small for each size fraction before compiling data for the stability tests just discussed. Specifically, we fitted a minimum area bounding rectangle around each grain, using PARTISAN. When the short width of the rectangle was smaller than the retaining sieve mesh size, the grain was discarded. For the $2-1 \mathrm{~mm}(-1$ to $0 \phi)$ to $0.5-$ $0.25 \mathrm{~mm}(+1$ to $+2 \phi)$ size fractions, the proportion of grains rejected is relatively low, comprising between $11 \%$ and $29 \%$ out of a total $46-69$ grains (Fig. 11). For the $0.25-0.125 \mathrm{~mm}$ $(+2$ to $+3 \phi)$ and $88-63 \mu \mathrm{m}(+3.5$ to $+4 \phi)$ fractions, the rejection rate becomes severe, spanning between $37 \%$ and $58 \%$ out of 75-156 grains.

\section{How morphometric and textural parameters vary with particle size}

Morphometric parameters and internal textures of our Ukinrek samples are partly dependent on the size fraction studied. In the Strombolian sample for example, median convexity increases from 0.4 to 0.8 as the grain size investigated decreases (Fig. 12, left). The change in convexity is more modest in the phreatomagmatic sample.

Median 2D crystallinity in the phreatomagmatic sample increases from $42 \%$ to $65 \%$ in progressively finer grains (Fig. 12 , right). In contrast, $2 \mathrm{D}$ crystallinity is more stable in the Strombolian sample.

In both samples, 2D vesicularity decreases globally with the size fraction (Fig. 13, left), from median values of over $25 \%$ for $2-1 \mathrm{~mm}(-1$ to $0 \phi)$, to $\sim 5 \%$ and less at $88-63 \mu \mathrm{m}(+3.5$ to $+4 \phi)$. In detail, the Strombolian sample is more vesicular (greater vesicle area) than the phreatomagmatic one at 2-1 mm $(-1$ to $0 \phi)$, but the phreatomagmatic sample is more vesicular at $88-63 \mu \mathrm{m}(+3.5$ to $+4 \phi)$.

The Büttner et al. (2002) plot, which uses the IPA parameters, was designed to be employed on ash grains $0.25-0.125 \mathrm{~mm}$ $(+2$ to $+3 \phi)$ or smaller, imaged as silhouettes. This diagram separates clasts inferred to have been produced by ductile vs. brittle fragmentation, based on the "Rectangularity $\mathrm{x}$ Compactness" product, indicated by a horizontal line. More recently, Dürig et al. (2018) revised this threshold, based on morphometric analyses of silhouettes for rhyolitic ash particles with grain size $<250 \mu \mathrm{m}$. Here we present resulting diagrams for all our size fractions, using particle cross-sections, to explore how grain size controls the position of fragments on the plot (Fig. 13, right). In our samples, the median values of "Rectangularity x Compactness" are strongly related to grain size.

Looking first at the fine fractions for which the diagram is intended, using the revised brittle-ductile cutoff proposed by Dürig et al. (2018) (purple line), a significant number of phreatomagmatic grains plot in the brittle field for the $0.25-$ $0.125 \mathrm{~mm}(+2$ to $+3 \phi)$ and $88-63 \mu \mathrm{m}(+3.5$ to $+4 \phi)$ plots, whereas almost all Strombolian grains fall in the ductile field. This suggests that this diagram can also be employed 
successfully on particle cross-sections, for these fine fractions. The distinction between Strombolian and phreatomagmatic based on "Rectangularity $\mathrm{x}$ Compactness" progressively breaks down for larger ash particles, with the $2-1 \mathrm{~mm} \mathrm{(-1} \mathrm{to} 0 \phi)$ fraction showing no difference between our samples. This was expected since the diagram was not designed for coarse ash.

\section{Discussion}

Choice of the optimum size fraction for particle crosssections

Particle cross-sections have the advantage of exposing the particle interiors to quantify vesicularity and crystallinity along with particle shape (they also allow measurement of the groundmass and crystal chemistry). Since morphometric and textural parameters depend on particle size, very strongly so for some parameters in some samples (Figs. 12, 13), it is necessary to select an 'optimal' size fraction for juvenile particle cross-sections in any standardized methodology for comparative studies of primary magma fragmentation. If all researchers use the same size fraction for particle cross-sections, and the same measurement method, results will be directly comparable.

Table 3 summarizes the pros and cons of the coarser versus finer size fractions we examined for particle cross-sections. Arguments include theoretical considerations, empirical results (the tests described above), and practical details influencing the time/user effort for different size fractions.

Theoretical and empirical considerations

The selected size fraction for particle cross-sections must ideally be found in the vast majority of natural pyroclastic deposits. Some types of pyroclastic deposits are ash-poor (e.g., proximal Hawaiian fallout), but the larger ash grains among those studied here (those from the $2-1 \mathrm{~mm}(-1$ to $0 \phi)$, to $0.5-0.25 \mathrm{~mm}(+1$ to $+2 \phi)$ fractions) should be found in most deposits.

To get good data on internal textures within the ash, larger grains are theoretically better suited since they more directly reflect the overall crystallinity and vesicularity of the magma prior to fragmentation. We do not think that the observed decrease in $2 \mathrm{D}$ vesicularity from $2-1 \mathrm{~mm}(-1$ to $0 \phi)$ to $88-63 \mu \mathrm{m}(+3.5$ to $+4 \phi)$ (Fig. 13) reflects strong post-fragmentation vesiculation in the coarser ash grains. Instead, as the grain size decreases, the large vesicles are progressively cut across during fragmentation, so the smaller grains are less representative.

For 2D crystallinity, the apparent increase of crystallinity in finer fractions for the phreatomagmatic sample reflects the tachylitic groundmass (Fig. 2d), as opposed to the glassy groundmass of the Strombolian sample (Fig. 2d). When acquiring multiple grains simultaneously, groundmass was better imaged in the finer fractions, since smaller particles necessitated higher magnifications. However, if the groundmass texture is of interest, a zoom can optionally be made on large ash grains to get the same information without sacrificing the larger crystals.
Practical considerations

Practical laboratory considerations also militate in favor of using relatively coarse ash. Both $0.71-0.5 \mathrm{~mm}(+0.5$ to $+1 \phi)$ and $0.5-0.25 \mathrm{~mm}(+1$ to $+2 \phi)$ size fractions, for instance, can be easily and quickly picked under the binocular microscope and prepared as PEGMs. They allow multiple grains per image during acquisition, speeding up the process. In contrast, the 2$1 \mathrm{~mm}(-1$ to $0 \phi)$ fraction necessitates significantly more pixels to get stable values (Figs. 6, 7; Table 1), and more time for image preparation prior to textural analysis. It may also cause imaging/distortion problems on some SEMs because the grains are large (L. Gurioli, pers. commun., 2020).

Final choice for particle cross-sections

Considering all these aspects, we propose that the $0.71-$ $0.5 \mathrm{~mm}(+0.5$ to $+1 \phi)$ size fraction is optimal for the determination of morphometric and textural parameters using particle cross-sections (Fig. 1). The $0.5-0.25 \mathrm{~mm}(+1$ to $+2 \phi)$ fraction would have been equally acceptable, but $0.71-0.5 \mathrm{~mm}$ $(+0.5$ to $+1 \phi)$ is evenly spaced on the $\phi$ scale between our recommended lapilli fraction $(8-4 \mathrm{~mm},-3$ to $-2 \phi)$ and our standard fine ash fraction $(88-63 \mu \mathrm{m},+3.5$ to $+4 \phi$; Ross et al. 2022).

Number of pixels for combined morphometric and textural measurements

Some previous studies have been focused on the fast measurement of morphometric parameters. This involved a moderate pixel density coupled with a large number of grains, in order to get stable average values for the morphometric parameters. In this study, we measured both textural and morphometric parameters, and determined that relatively high values of pixel density are required. The parameters that needed the most pixels to stabilize are convexity (which never fully stabilizes, since it is a perimeter-based measure) and the textural parameters. Interestingly, the higher pixel density proposed in this study ultimately allowed a much lower number of juvenile grains to be processed, as detailed in the next section.

Number of juvenile grains for particle cross-section studies Previous morphometric parameter studies have called for large numbers of grains to be analyzed in each sample. There is a perception that thousands of grains might be needed (Durant et al. 2009; Liu et al. 2015). Here we show that using high-quality SEM-BSE images of particle cross-sections for the selected $0.71-0.5 \mathrm{~mm}(+0.5$ to $+1 \phi)$ size fraction, in our samples, analyzing approximately 20 grains would be sufficient to obtain stable averages in morphometric and textural parameters. Taking into account that other samples may be more complex than ours (e.g., polymodal distributions), and that up to a quarter of imaged grains may be rejected due to particle size considerations (Fig. 11), we recommend selecting, mounting and imaging 50 juvenile grains per sample (Fig. 1). Once again, this value proved to be sufficient to characterize the whole population, but more grains would be needed to characterize each subpopulation in detail, if those subpopulations are of interest.

This number of grains should be tested in future studies with other samples. In these future studies, stability of 
morphometric and textural parameters can be verified by calculating the relative differences in the cumulative average shape parameters for the $45^{\text {th }}, 46^{\text {th }}, 47^{\text {th }}, 48^{\text {th }}$, and $49^{\text {th }}$ grains. If the relative differences exceed $5 \%$, more grains should be imaged and analyzed.

\section{Importance of sample preparation and imaging}

In supporting the chain of standard steps (Fig. 1), careful manufacture of PEGMs and attention to the quality of SEM images acquired for juvenile particle cross-sections are very important. The quality of the morphometric and textural measurements ultimately depends on the care employed during these steps.

\section{PEGM manufacture}

Mounting grains with the longest axis parallel to the mounting plane ensures that $2 \mathrm{D}$ aspect ratios give a good idea of 3D particle elongations. Other particle orientations, especially for some elongate grains, might produce "too small" cross sectional areas, resulting in the grain being rejected during filtering.

The stages of mounting, grinding and polishing have to be done carefully. It is crucial to mount the grains on a very flat surface; in addition, one must make sure that the liquid epoxy has a low viscosity and does not lift the grains up. Finally, grinding/polishing a PEGM too much (or not enough) may result in the cross-section being discarded during data filtering (Fig. 11). Our tests show that with careful PEGM manufacturing, a relatively low rejection rate can be maintained for the $0.71-0.5 \mathrm{~mm}(+0.5$ to $+1 \phi)$ size fraction. In contrast, the high rejection rates observed for the finer ash PEGMs (i.e., $0.25-0.125 \mathrm{~mm}$ or +2 to $+3 \phi$, and $88-63 \mu \mathrm{m}$ or +3.5 to $+4 \phi)$ are, in our experience, imputable to difficulties in consistent PEGM preparation that result from interactions of these small grains with epoxy, and electrostatic forces.

In summary, we aim to capture the longest axis of the particle in 2D and expose its center normal to this dimension. These conditions offer the best chances to preserve as much $3 \mathrm{D}$ information as possible during the "conversion" of the grains into cross-sectional slices.

\section{SEM image acquisition}

The most crucial aspect of SEM-BSE image acquisition on particle cross-sections is to obtain an image with sharply contrasted internal phases (i.e., the groundmass relative to the crystal phases). This requires (i) a high enough pixel density (the combination of magnification and image resolution), (ii) an appropriate scan-speed setting, and (iii) optimal adjustment of brightness and contrast settings within the SEM image acquisition software. Obtaining sharp contrast during acquisition will ease subsequent image preparation by minimizing the need for adjustments of grey levels within the image. Furthermore, this will speed up image segmentation, i.e. greyscale thresholding of each crystal phase and vesicles. A poorly contrasted image, however, will lead to erroneously segmented particle crosssections, potentially leading to severe underestimation/overestimation of 2D crystallinity and 2D vesicularity of the sample. In addition, features such as groundmass or specific crystal types should ideally have the same grey levels for different clasts within a whole sample, in order to allow batch processing during image segmentation. In our tests, such conditions were easily met for the $0.71-0.5 \mathrm{~mm}$ $(+0.5$ to $+1 \phi)$ size fraction, due to the relatively small magnification and reduced scan time for each image. Reduced scan time minimizes charging, which is probably responsible for observed temporal drifts in brightness. For some magma compositions where crystal density approaches that of the glass in the groundmass (e.g., plagioclase-bearing felsic pyroclasts), extra care should be applied in obtaining the best possible contrast between the two phases.

\section{Conclusions}

Together, this study and its companion paper (Ross et al. 2022) constitute an initial proposal for a standardized methodology to characterize juvenile pyroclasts for comparative fragmentation studies. A standardized methodology will allow the volcanological community to generate data that is reproducible and can be compared between different volcanoes and different laboratories. Ultimately, we hope that this will lead to the generation of a large database covering all the main eruptive styles and magma compositions, which would allow volcanologists to gain more insights on fragmentation processes. It would therefore also have potential implications for volcano monitoring and eruption forecasting.

This study defines key points of the standardized protocol for the analysis of primary juvenile pyroclasts using polished epoxy grain mounts (PEGMs) and SEM-BSE imaging of particle cross-sections:

(1) It is important to correctly prepare and image the grains in order to obtain high-quality particle images suitable for shape and textural analysis;

(2) Compared to previous studies that analyzed only morphometric parameters, a higher number of pixels per particle between 10000 and 75000 is required to also measure 2D crystallinity and 2D vesicularity on each particle cross-section, respectively for 88-63 $\mu \mathrm{m}(+3.5$ to $+4 \phi)$ and $2-1 \mathrm{~mm}(-1$ to $0 \phi)$ size fractions;

(3) Using a specific sieved size fraction and high-quality SEM images, 50 grains are needed in order to obtain stable averages in morphometric parameters, a much lower number compared to suggestions from many previous studies;

(4) We propose that the $0.71-0.5 \mathrm{~mm}(+0.5$ to $+1 \phi)$ size fraction is optimal for joint morphometric and textural studies using particle cross-sections, based on a range of theoretical, empirical and practical considerations.

Moreover, we provide detailed instructions for PEGM preparation. Such information is commonly omitted in publications, but crucial to obtain reproducible data. Finally, we developed the script package "PASTA", which facilitates image preparation and allows the semi-automated processing of both particle cross-sections and silhouettes, followed by the 
accurate measurement of 2D morphometric and/or textural parameters.

\section{Acknowledgements}

This study was funded by a Discovery Grant to PSR from the Natural Sciences and Engineering Research Council of Canada (NSERC) (RGPIN-2015-06782). TD is supported by the Icelandic Research Fund (Rannís), grant Nr. 206527051. We thank Ikbel Mouedhen, Philippe Girard and Arnaud De Coninck for the support during the development of the polishing technique. We acknowledge Caroline Bélanger, Sarah Galloway and Félix Gagnon for the support in sample preparation and data processing. We thank Jacopo Taddeucci, Lucy Porritt and Pierre Francus for their comments on a draft of this paper. We thank Erin Fitch, an anonymous reviewer and associate editor Benjamin J. Andrews for constructive journal reviews.

\section{References}

Avery MR, Panter KS, Gorsevski PV (2017) Distinguishing styles of explosive eruptions at Erebus, Redoubt and Taupo volcanoes using multivariate analysis of ash morphometrics. J Volcanol Geotherm Res 332:1-13

Bagheri GH, Bonadonna C, Manzella I, Vonlanthen P (2015) On the characterization of size and shape of irregular particles. Powder Technol. 270:141-153

Büttner R, Dellino P, Zimanowski B (1999) Identifying magma-water interaction from the surface features of ash particles. Nature 401:688-690

Büttner R, Dellino P, La Volpe L, Lorenz V, Zimanowski B (2002) Thermohydraulic explosions in phreatomagmatic eruptions as evidenced by the comparison between pyroclasts and products from Molten Fuel Coolant Interaction experiments. J Geophys Res Solid Earth 107(B11):ECV 5-1-ECV 5-14

Cioni R, D'Oriano C, Bertagnini A (2008) Fingerprinting ash deposits of small scale eruptions by their physical and textural features. J Volcanol Geotherm Res 177:277-287

Cioni R, Pistolesi M, Bertagnini A, Bonadonna C, Hoskuldsson A, Scateni B (2014) Insights into the dynamics and evolution of the 2010 Eyjafjallajökull summit eruption (Iceland) provided by volcanic ash textures. Earth Planet Sci Lett 394 (Supplement C):111-123

Cioni R, Sbrana A, Vecci R (1992) Morphologic features of juvenile pyroclasts from magmatic and phreatomagmatic deposits of Vesuvius. J Volcanol Geotherm Res 51:61-78

Comida PP, Ross P-S (2021) PierCVolc/PASTA: PASTA project (Version 3.7, February 22, 2021), http://doi.org/10.5281/zenodo.3336335

Comida PP, Ross P-S, Dürig T, White JDL, Lefebvre NS (2021) SEM_raw_images_Comida_et_al_2021 (Version 2, October 5, 2021), http://doi.org/10.5281/zenodo.4639399

Dellino P, La Volpe L (1996) Image processing analysis in reconstructing fragmentation and transportation mechanisms of pyroclastic deposits. The case of
Monte Pilato-Rocche Rosse eruptions, Lipari (Aeolian islands, Italy). J Volcanol Geotherm Res 71:13-29

Dellino P, Gudmundsson MT, Larsen G, Mele D, Stevenson JA, Thordarson T, Zimanowski B (2012) Ash from the Eyjafjallajökull eruption (Iceland): fragmentation processes and aerodynamic behavior. J Geophys Res 117:B00C04. https://doi.org/10.1029/2011JB008726

D'Oriano C, Bertagnini A, Cioni R, Pompilio M (2014) Identifying recycled ash in basaltic eruptions. Sci Rep 4:5851

Dioguardi F, Mele D, Dellino P, Dürig T (2017) The terminal velocity of volcanic particles with shape obtained from 3D X-ray microtomography. J Volcanol Geotherm Res 329:41-53

Durant AJ, Rose WI, Sarna-Wojcicki AM, Carey S, Volentik ACM (2009) Hydrometeor-enhanced tephra sedimentation: constraints from the 18 May 1980 eruption of Mount St. Helens. J Geophys Res 114:B03204

Dürig T, Zimanowski B (2012) "Breaking news" on the formation of volcanic ash: Fracture dynamics in silicate glass. Earth Planet Sci Lett 335-336:1-8

Dürig T, Mele D, Dellino P, Zimanowski B (2012) Comparative analyses of glass fragments from brittle fracture experiments and volcanic ash particles. Bull Volc 74:691-704

Dürig T, Bowman MH, White JD, Murch A, Mele D, Verolino A, Dellino P (2018) PARTIcle Shape ANalyzer PARTISAN-an open source tool for multi-standard twodimensional particle morphometry analysis. Ann Geophys-Italy 61:31

Dürig T, Schmidt LS, White JDL, Bowman MH (2020a) DendroScan: an open source tool to conduct comparative statistical tests and dendrogrammatic analyses on particle morphometry. Sci. Rep. 10: article 21682

Dürig T, White JDL, Zimanowski B, Büttner R, Murch A, Carey RJ (2020b) Deep-sea fragmentation style of Havre revealed by dendrogrammatic analyses of particle morphometry. Bull. Volc. 82:article 67

Dürig T, White JDL, Murch AP, Zimanowski B, Büttner R, Mele D, Dellino P, Carey RJ, Schmidt LS, Spitznagel N (2020c) Deep-sea eruptions boosted by induced fuelcoolant explosions. Nat Geosci 13:498-503

Dürig T, Bowman HM (2021) lsschmidt/PARTISAN (Version 2.0, March 10, 2021), doi: 10.5281/zenodo.4593833

Dürig T, Ross P-S, Dellino P, White JDL, Mele D, Comida PP (2021) A review of statistical tools for morphometric analysis of juvenile pyroclasts. Bull. Volc. 83:article 79

Freundt A, Rosi M (1998) From magma to tephra. Elsevier, New York

Heiken G (1972) Morphology and petrography of volcanic ashes. Geol Soc Am Bull 83:1961-1988

Heiken G, Wohletz K (1985) Volcanic ash. University of California Press, Berkeley

Hornby AJ (2018) IPC shape macro (Version 1.0.2, September 28, 2018), http://doi.org/10.5281/zenodo.1438445

Jordan S, Dürig T, Cas RAF, Zimanowski B (2014) Processes controlling the shape of ash particles: results of statistical IPA. J Volcanol Geotherm Res 288:19-27

Kienle J, Kyle PR, Self S, Motyka RJ, Lorenz V (1980) Ukinrek Maars, Alaska, I. April 1977 eruption sequence, 
petrology and tectonic setting. J Volcanol Geotherm Res 7:11-37

Lautze NC, Houghton BF (2007) Linking variable explosion style and magma textures during 2002 at Stromboli volcano, Italy. Bull Volcanol 69:445-460

Leibrandt S, Le Pennec J-L (2015) Towards fast and routine analyses of volcanic ash morphometry for eruption surveillance applications. J Volcanol Geotherm Res 297:11-27

Liu EJ, Cashman KV, Rust AC (2015) Optimising shape analysis to quantify volcanic ash morphology. GeoResJ 8:14-30

Liu EJ, Cashman KV, Rust AC, Höskuldsson A (2017) Contrasting mechanisms of magma fragmentation during coeval magmatic and hydromagmatic activity: the Hverfjall Fires fissure eruption, Iceland. Bull Volc 79:article 68

Mele D, Dioguardi F (2018) The grain size dependency of vesicular particle shapes strongly affects the drag of particles. First results from microtomography investigations of Campi Flegrei fallout deposits. J Volcanol Geotherm Res 353:18-24

Mele D, Dellino P, Sulpizio R, Braia G (2011) A systematic investigation on the aerodynamics of ash particles. $\mathrm{J}$ Volcanol Geotherm Res 203:1-11

Mele D, Dioguardi F, Dellino P (2018) A study on the influence of internal structures on the shape of pyroclastic particles by X-ray microtomography investigations. Ann Geophys-Italy 61:AC27

Ort MH, Lefebvre NS, Neal CA, McConnell VS, Wohletz KH (2018) Linking the Ukinrek 1977 maar-eruption observations to the tephra deposits: New insights into maar depositional processes. J Volcanol Geotherm Res 360:36-60

Porritt L, Russell J, Quane S (2012) Pele's tears and spheres: Examples from Kilauea Iki. Earth Planet Sci Lett 333:171-180

Rausch J, Grobéty B, Vonlanthen P (2015) Eifel maars: Quantitative shape characterization of juvenile ash particles (Eifel Volcanic Field, Germany). J Volcanol Geotherm Res 291:86-100

Ross P-S, Dürig T, Comida PP, Lefebvre NS, White JDL, Andronico D, Thivet S, Eychenne J, Gurioli L (2022) Standardized analysis of juvenile pyroclasts in comparative studies of primary magma fragmentation; 1. Overview and workflow. Bull Volc. https://doi.org/10.1007/s00445-021-01516-6
Rust AC, Cashman KV (2011) Permeability controls on expansion and size distributions of pyroclasts. J Geophys Res 116(B11)

Schindelin J, Arganda-Carreras I, Frise E, Kaynig V, Longair M, Pietzsch T, Preibisch S, Rueden C, Saalfeld S, Schmid B, Tinevez J-Y, White DJ, Hartenstein V, Eliceiri K, Tomancak P, Cardona A (2012) Fiji: an open-source platform for biological-image analysis. Nat Methods 9:676

Schipper CI, Castro JM, Tuffen H, James MR, How P (2013) Shallow vent architecture during hybrid explosiveeffusive activity at Cordón Caulle (Chile, 2011-12): evidence from direct observations and pyroclast textures. J Volcanol Geotherm Res 262:25-37

Schmith J, Höskuldsson Á, Holm PM (2017) Grain shape of basaltic ash populations: implications for fragmentation. Bull Volc 79:article 14

Schneider CA, Rasband WS, Eliceiri KW (2012) NIH Image to ImageJ: 25 years of image analysis. Nat Methods 9:671-675

Shea T, Houghton B, Gurioli L, Cashman K, Hammer J, Hobden B, Stovall W, Carey R (2010a) SEM image processing with Photoshop. University of Hawaii and University of Oregon, USA, http://www.soest.hawaii.edu/GG/FACULTY/tshea/foam s/methodsimrec.html

Shea T, Houghton BF, Gurioli L, Cashman KV, Hammer JE, Hobden BJ (2010b) Textural studies of vesicles in volcanic rocks: An integrated methodology. J Volcanol Geotherm Res 190:271-289

Verolino A, White JDL, Dürig T, Cappuccio F (2019) Black Point - Pyroclasts of a Surtseyan eruption show no change during edifice growth to the surface from $100 \mathrm{~m}$ water depth. J Volcanol Geotherm Res 384:85-102

Vonlanthen P, Rausch J, Ketcham RA, Putlitz B, Baumgartner LP, Grobéty B (2015) High-resolution 3D analyses of the shape and internal constituents of small volcanic ash particles: The contribution of SEM micro-computed tomography (SEM micro-CT). J Volcanol Geotherm Res 293:1-12

White J, Houghton B (2006) Primary volcaniclastic rocks. Geology 34:677-680

Zimanowski B, Büttner R, Lorenz V, Häfele HG (1997) Fragmentation of basaltic melt in the course of explosive volcanism. J Geophys Res Solid Earth 102:803-814 


\section{Tables}

Table 1. Optimum values of pixels per particle (pixel density) for SEM image processing of particle cross-sections

\begin{tabular}{lll}
\hline Size fraction & & Pixel density \\
\hline$\mu \mathrm{m}$ & $\phi$ & \\
\hline $2000-1000$ & -1 to 0 & 75,000 \\
$710-500$ & +0.5 to +1 & 20,000 \\
$500-250$ & +1 to +2 & 10,000 \\
$250-125$ & +2 to +3 & 10,000 \\
$88-63$ & +3.5 to +4 & 10,000 \\
\hline
\end{tabular}

Table 2 Number of juvenile fragments needed to reach a stable average in morphometric and textural parameters, as a function of grain size, for Ukinrek samples

\begin{tabular}{llllll}
\hline Size fraction & & Strombolian & & Phreatomagmatic \\
$\mu \mathrm{m}$ & $\phi$ & $\begin{array}{l}\text { Visual estimate } \\
\text { on graphs }\end{array}$ & $\begin{array}{l}5 \% \text { variation } \\
\text { cut-off }\end{array}$ & $\begin{array}{l}\text { Visual estimate } \\
\text { on graphs }\end{array}$ & $\begin{array}{l}5 \% \text { variation cut- } \\
\text { off }\end{array}$ \\
\hline $2000-1000$ & -1 to 0 & $\sim 25$ & 20 & $\sim 20$ & 72 \\
$710-500$ & +0.5 to +1 & $10-15$ & 5 & $\sim 20$ & 9 \\
$500-250$ & +1 to +2 & $\sim 20$ & 17 & $\sim 20$ & 22 \\
$250-125$ & +2 to +3 & $\sim 30$ & 11 & $\sim 30$ & 22 \\
$88-63$ & +3.5 to +4 & $\sim 40$ & 28 & $\sim 30$ & 22 \\
\hline
\end{tabular}


Table 3 Pros and cons of different ash size fractions for measurement of morphometric and textural parameters on particle crosssections

\begin{tabular}{|c|c|c|}
\hline Size fractions & $\begin{array}{l}2000-1000,710-500,500-250 \mu \mathrm{m} \\
(-1 \text { to } 0 \phi,+0.5 \text { to }+1 \phi,+1 \text { to }+2 \phi)\end{array}$ & $\begin{array}{l}250-125,88-63 \mu \mathrm{m} \\
(+2 \text { to }+3 \phi,+3.5 \text { to }+4 \phi)\end{array}$ \\
\hline Pros & 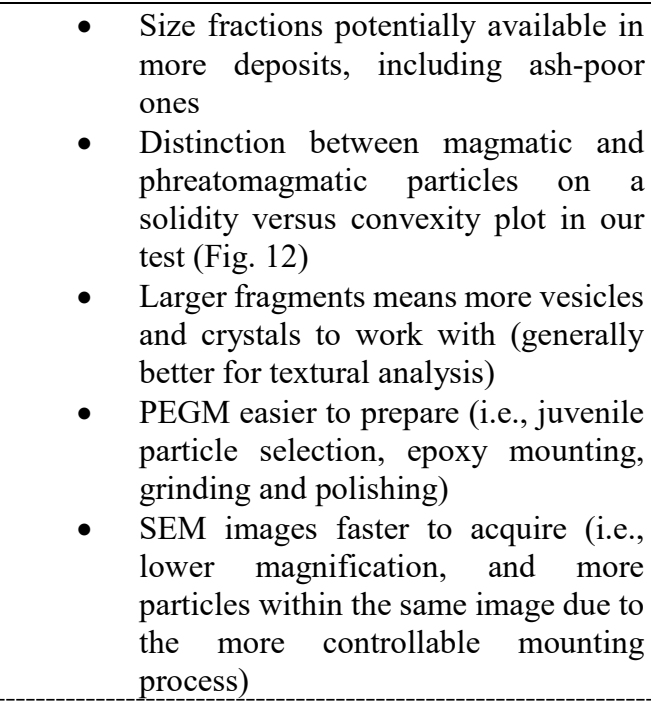 & $\begin{array}{l}\text { - Better observation of the groundmass } \\
\text { including small crystals (if present) as the } \\
\text { magnification is normally higher* } \\
\text { Büttner et al. (2002) diagram can } \\
\text { potentially be applied to assess the } \\
\text { prevalence of brittle and ductile } \\
\text { fragmentation, even though this diagram } \\
\text { was designed for particle silhouettes }\end{array}$ \\
\hline Cons & $\begin{array}{l}\text { - Image pre-processing in Photoshop } \\
\text { takes longer, as more vesicles might } \\
\text { need to be blackened and fractures } \\
\text { repaired } \\
\text { For } 2-1 \mathrm{~mm}(-1 \text { to } 0 \phi) \text { only, the } \\
\text { relatively large size of the grains and } \\
\text { the very high number of pixels/particle } \\
\text { needed (Table } 1) \text { result in fewer grains } \\
\text { per image and therefore, an overall } \\
\text { longer image acquisition time }\end{array}$ & $\begin{array}{l}\text { - Very small grains are difficult to handle, } \\
\text { mount and polish, resulting in a high } \\
\text { particle rejection rate (Fig. 11) } \\
\text { These smaller clasts are missing large } \\
\text { crystals and vesicles (vesicularity and } \\
\text { crystallinity are not representative) } \\
\text { Imaging becomes long and difficult: } \\
\text { - necessitates higher magnification } \\
\text { and resolution } \\
\text { long acquisition times due to } \\
\text { higher magnification and possibly } \\
\text { fewer grains per image due to the } \\
\text { trickier mounting process } \\
\text { smaller spot size } \\
\text { extreme brightness and contrast } \\
\text { settings, resulting in blurred } \\
\text { images }\end{array}$ \\
\hline
\end{tabular}

$\bar{*}$ But if the groundmass is of interest, it can be studied by zooming on the groundmass within grains from a coarser size fraction. 
Figures

STANDARD STEPS ONLY

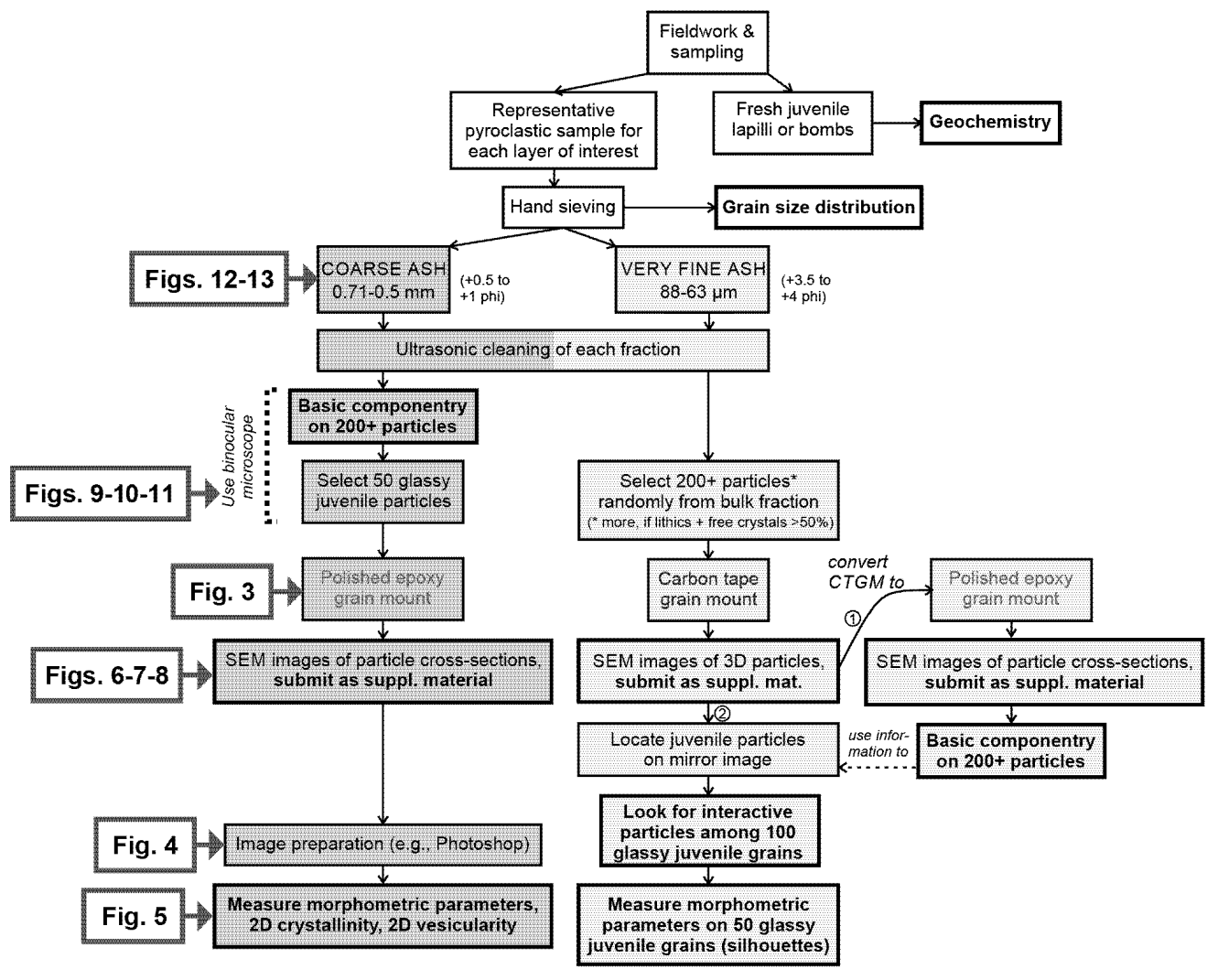

Fig. 1. Expanded version of the standard steps from Ross et al. (2022) highlighting the contributions detailed in this work. 

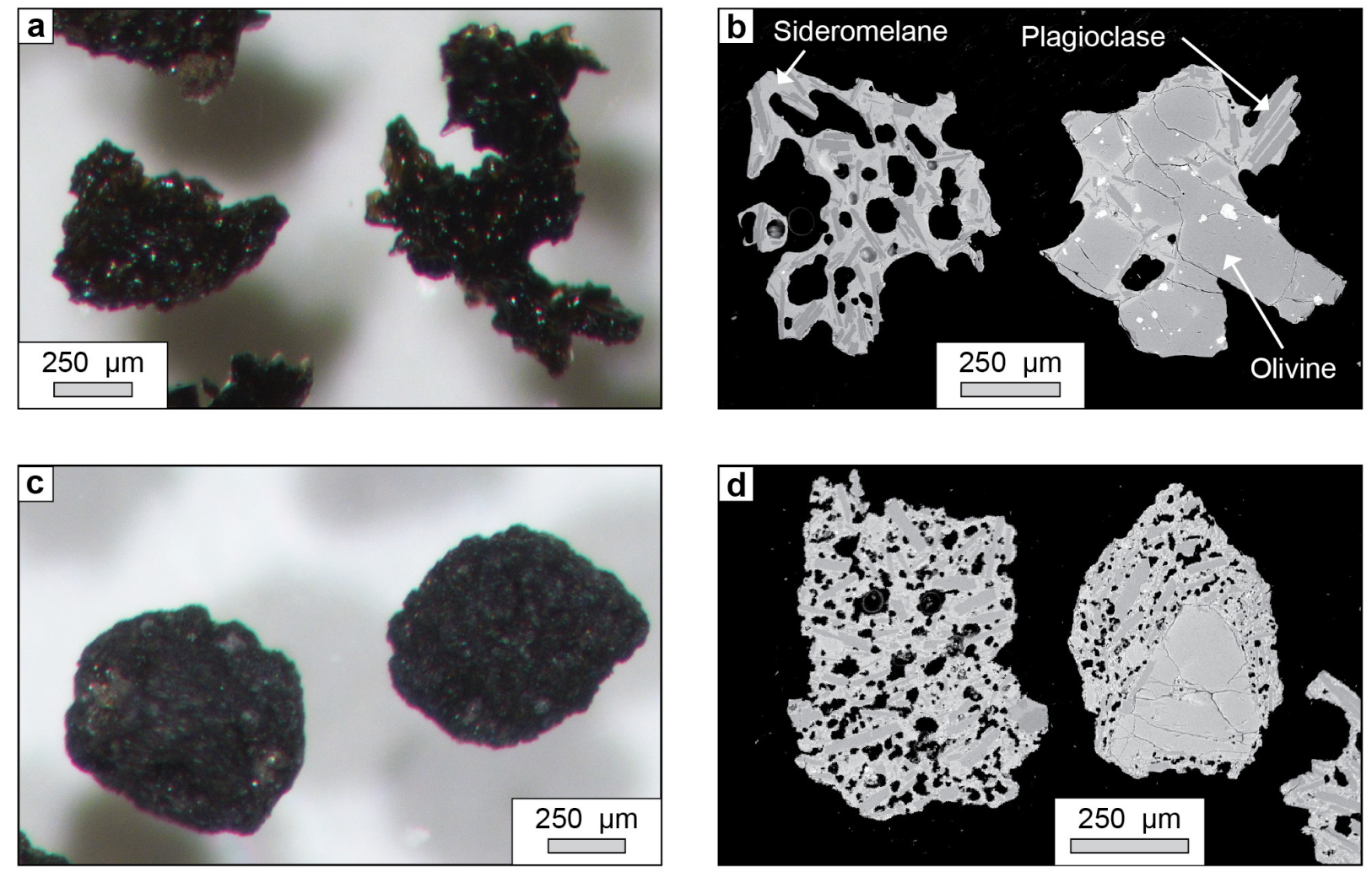

Fig. 2. Representative images of juvenile particles from the two basaltic Ukinrek test samples. For each sample, both binocular microscope (left) and SEM-BSE particle cross-sections views (right) are presented: (a-b) Strombolian; (c-d) phreatomagmatic. 

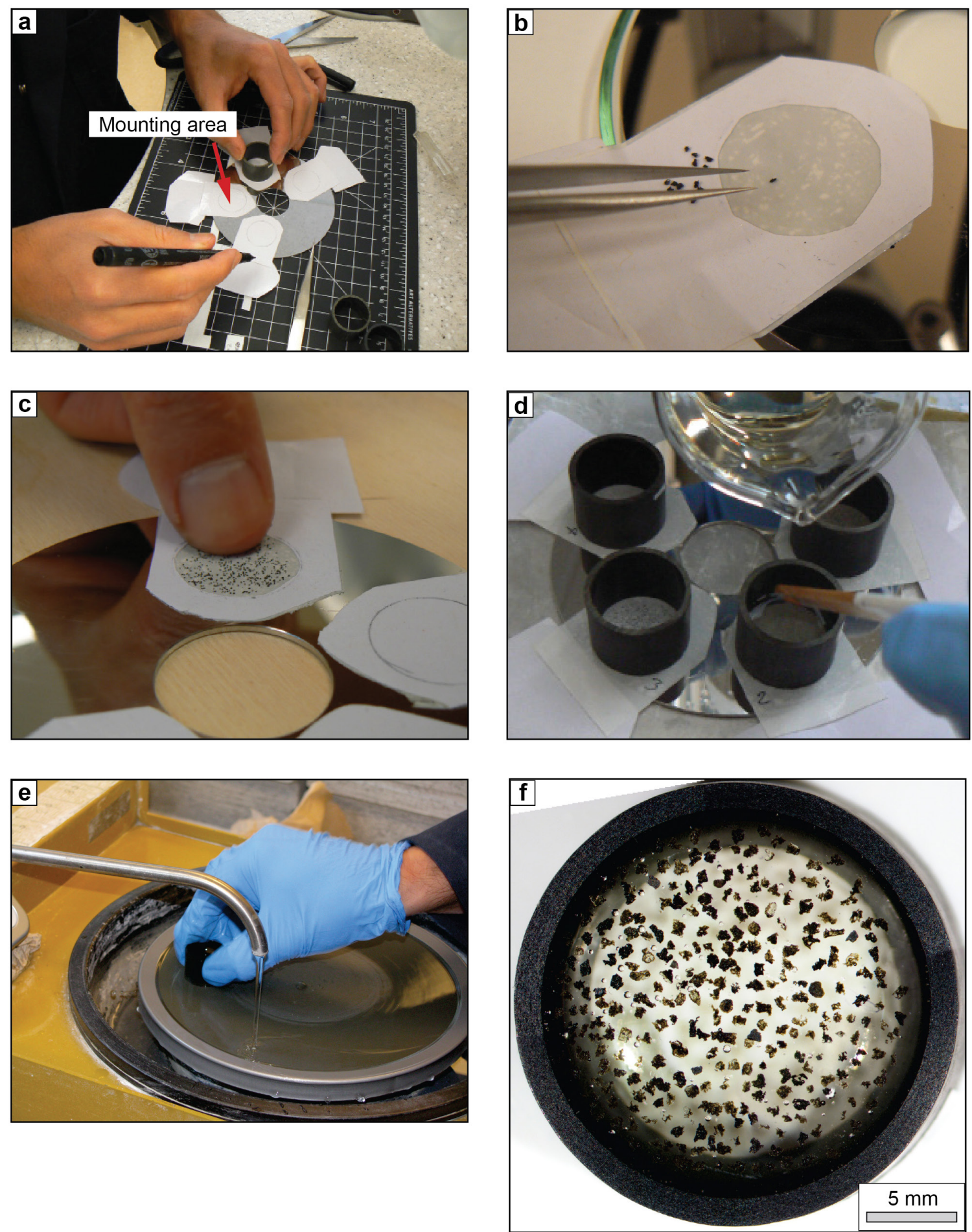

Fig. 3. Preparing a polished epoxy grain mount. (a) Placing the double-sided tape on a hard drive platter and marking the mounting area. The ringform is 1 inch $(2.54 \mathrm{~cm}$ ) in diameter. (b) View of particle transfer method for coarser particles (size fractions $2-1 \mathrm{~mm}$ or -1 to $0 \phi$, to $0.5-0.25 \mathrm{~mm}$ or +1 to $+2 \phi$ ). (c) View of "thumb" particle transfer method for finer particles (size fractions $0.25-0.125 \mathrm{~mm}$ or +2 to $+3 \phi$, and $88-63 \mu \mathrm{m}$ or +3.5 to $+4 \phi$ ). (d) Pouring the epoxy into the ring form. (e) View of the grinding stage with abrasive paper. (f) The finished PEGM under the binocular microscope (Strombolian sample from Ukinrek, $0.71-0.5 \mathrm{~mm}$ or +0.5 to $+1 \phi)$. 

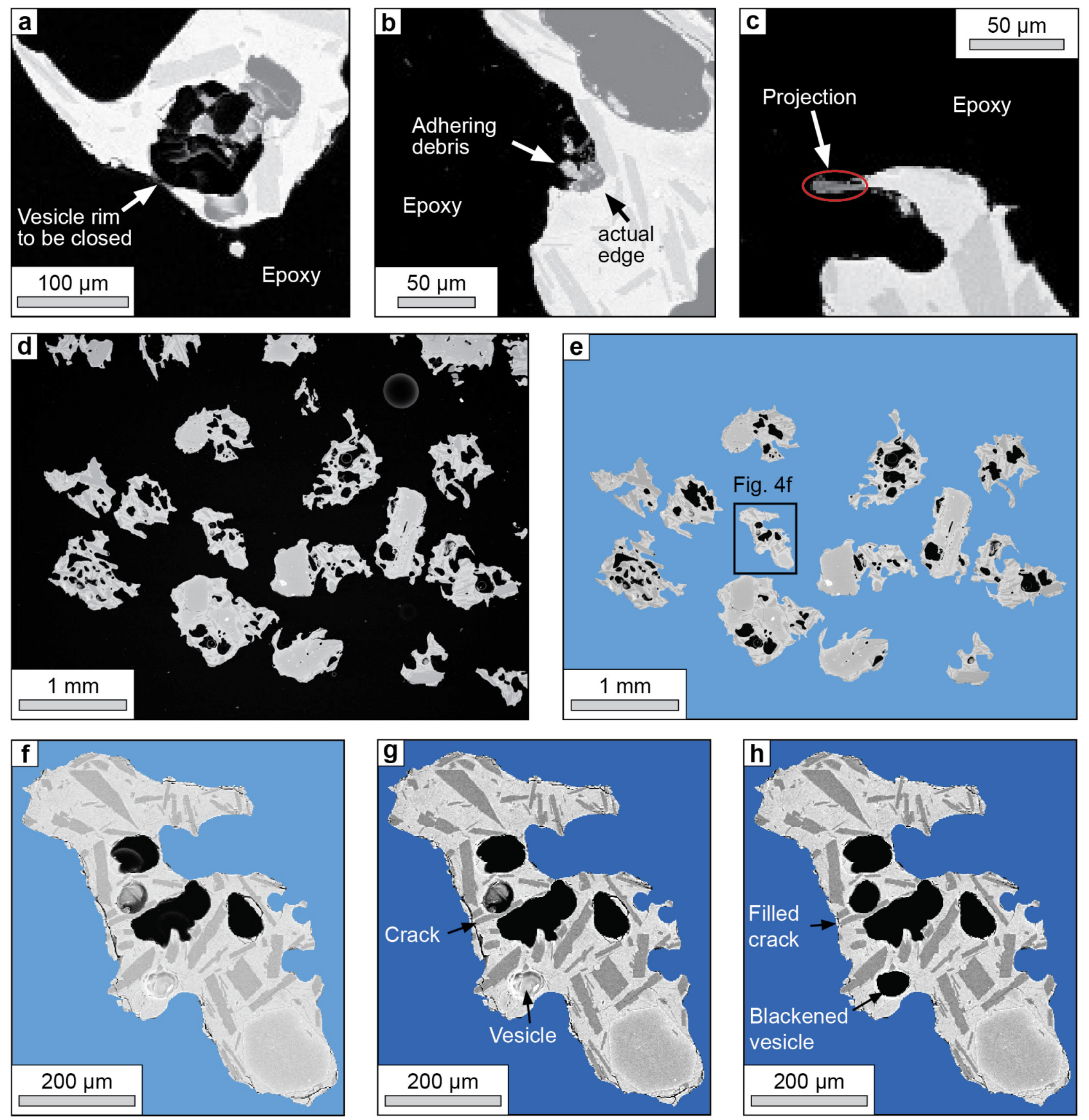

Fig. 4. Image preparation in Photoshop. (a) Closing vesicles. (b) Removing adhering debris misinterpreted as particle edge. (c) Including thin projections in the particle outline. (d) A typical image of the $0.71-0.5 \mathrm{~mm}(+0.5$ to $+1 \phi)$ fraction in BSE mode (same Ukinrek Strombolian sample as in Fig. 2b). (e) Replacing the background with a uniform blue color and deleting particles touching the edge of the image (as well as those that are obviously too small or inferred to be lithics). (f) Zoom on one of the juvenile particles from Fig. 4e, internal texture unrefined. (g) Appearance of Fig. $4 \mathrm{f}$ if the contrast between crystals and glassy groundmass is enhanced on Fig. 4e by adjusting the grey levels. (h) Manually blackening vesicles and filling the cracks. 

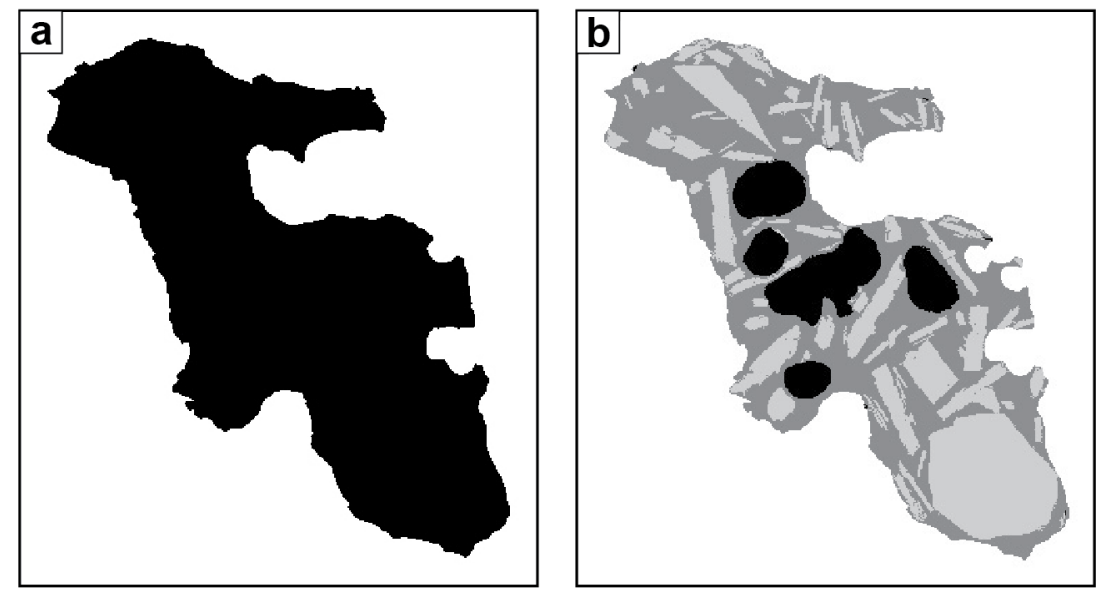

Fig. 5. Final image outputs of the PASTA script for Fiji. (a) View of the binary image file generated to measure shape parameters. (b) View of the false-color segmented greyscale image generated to measure 2D crystallinity and 2D vesicularity. 

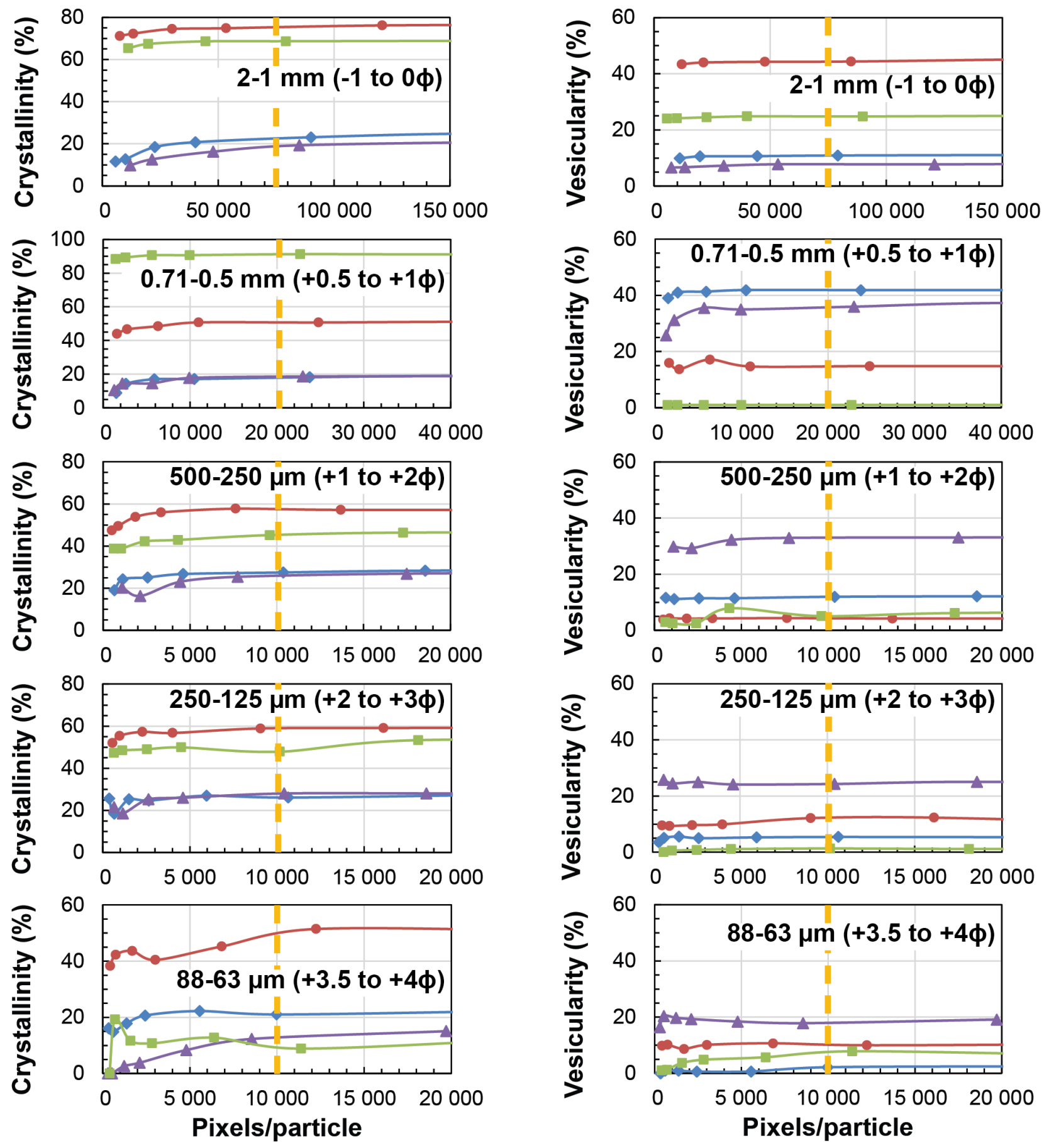

$\begin{array}{ll}\longrightarrow \text { Grain } 1 & - \text { Grain } 3 \\ \longrightarrow \text { Grain } 2 & \longrightarrow \text { Grain } 4\end{array}$

Optimum pixel number

Fig. 6. Pixel number test for 2D crystallinity and 2D vesicularity, using the Ukinrek Strombolian sample. In figures 6 and 7, four grains were tested for each size fraction, covering the highest and lowest crystallinity as well as the highest and lowest vesicularity. Each trend line corresponds, within a single size fraction, to the same grain. The vertical dashed lines indicate the optimum pixel numbers for each size fraction (all parameters considered, see also Fig. 7). 

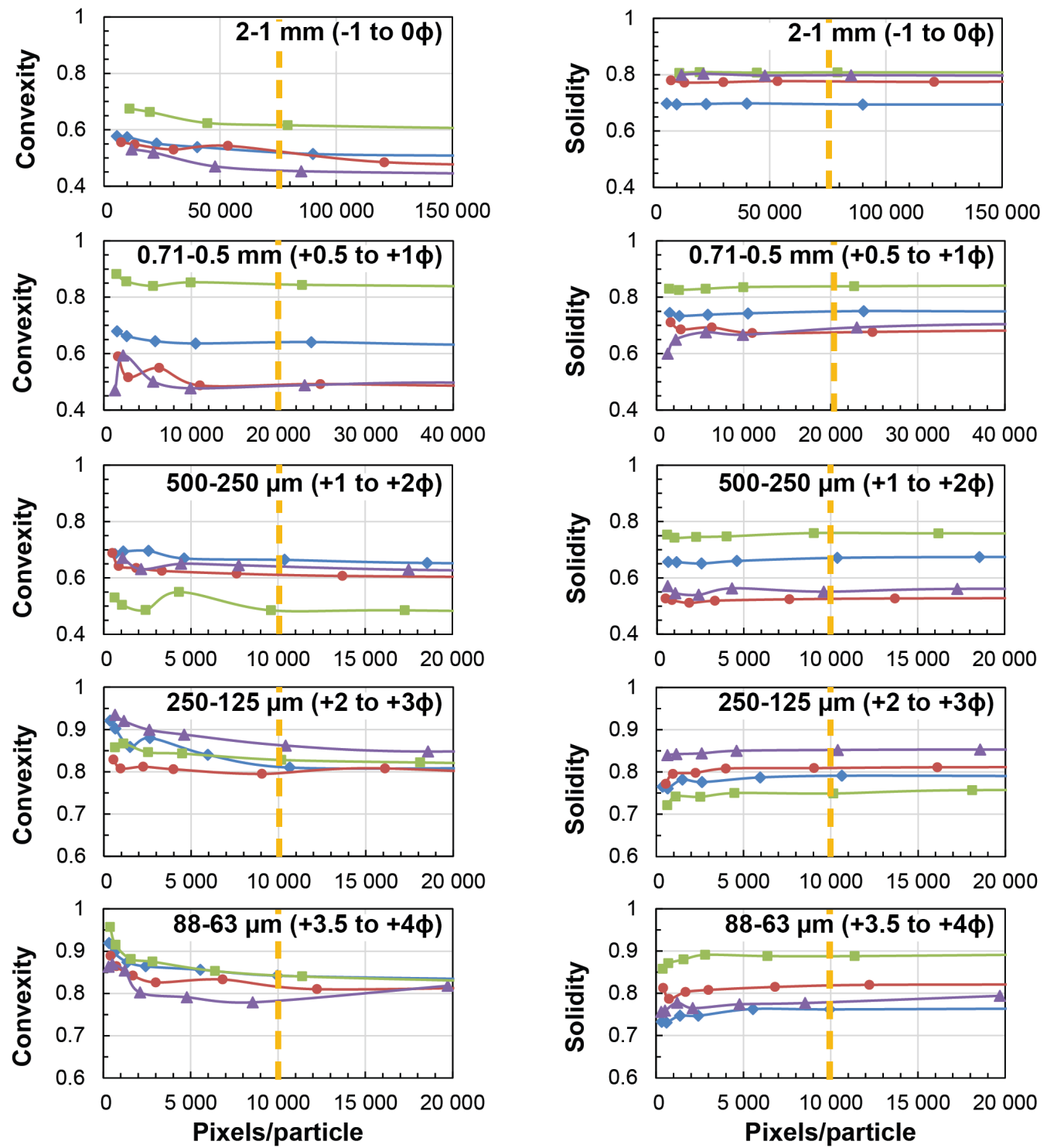

\begin{tabular}{|c|c|c|}
\hline $\begin{array}{l}\longrightarrow \text { Grain } 1 \\
\longrightarrow \text { Grain } 2\end{array}$ & $\begin{array}{l}- \text { Grain } 3 \\
- \text { Grain } 4\end{array}$ & Optimum pixel number \\
\hline
\end{tabular}

Fig. 7. Pixel number test for convexity and solidity, using the Ukinrek Strombolian sample. 

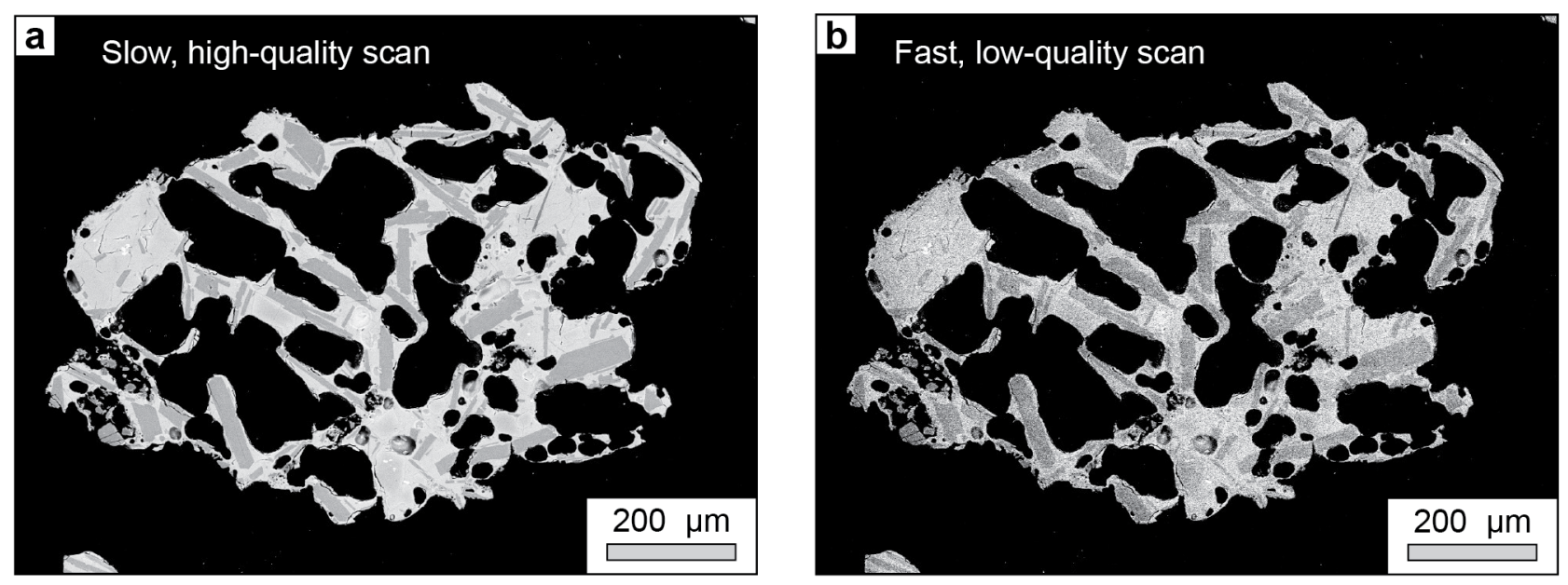

Fig. 8. SEM-BSE images of the same particle cross-section taken at the same magnification (68X) and resolution (2048 x 1536 pixels), but different scan speeds. (a) Slow, high-quality scan (about $160 \mathrm{sec}$ ) (b) Fast, low-quality scan (about $5 \mathrm{sec}$ ). 


\section{Magmatic}

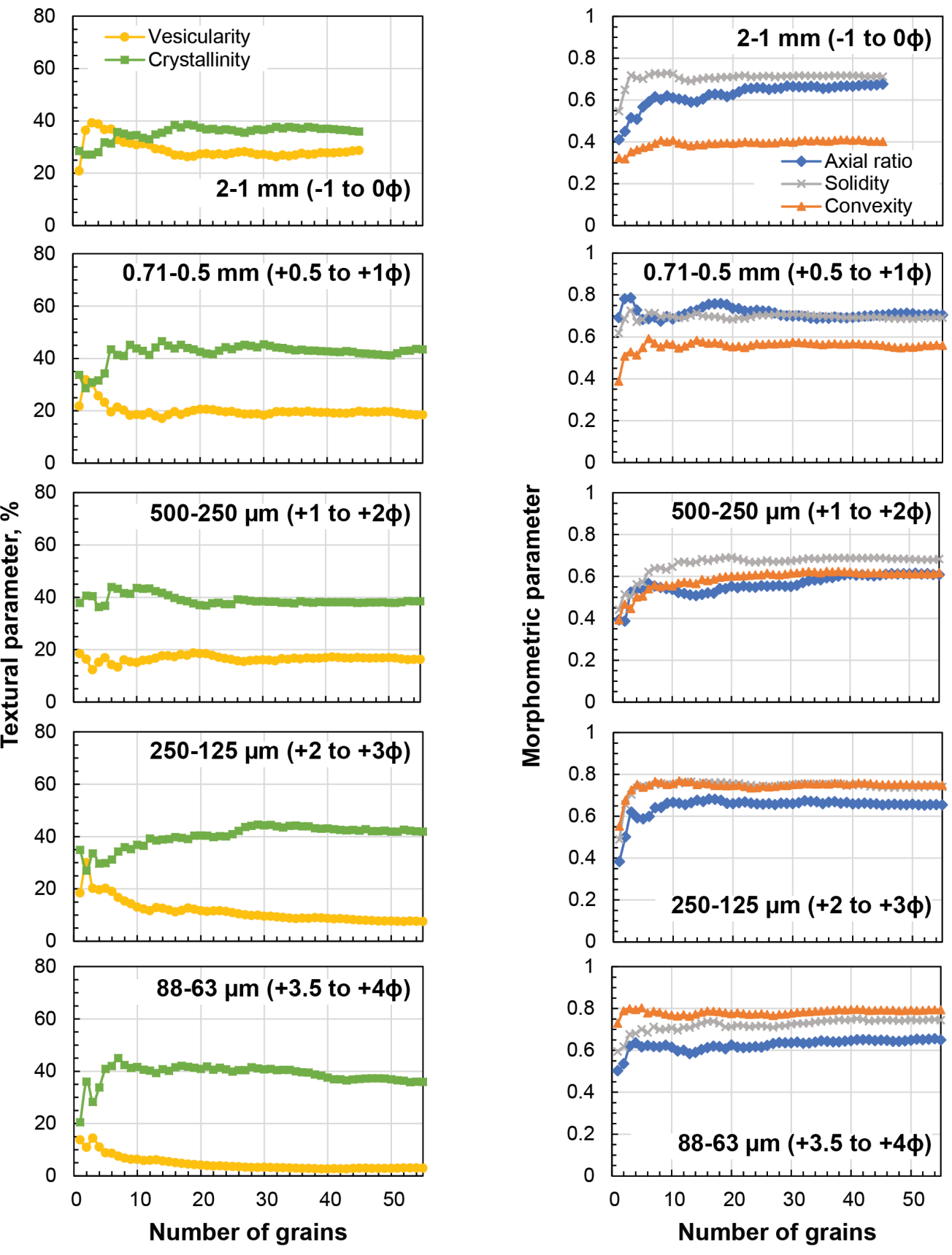

Fig. 9. Stability test to find the optimum number of grains for each size fraction, using the Strombolian sample from Ukinrek. The average values of 2D crystallinity, 2D vesicularity and three morphometric parameters stabilize as more grains are added. After filtering out the grains that were too small, more than 50 grains were measured for each size fraction except for the 2$1 \mathrm{~mm}(-1$ to $0 \phi)$ fraction, for which fewer grains had unfortunately been mounted. 


\section{Phreatomagmatic}
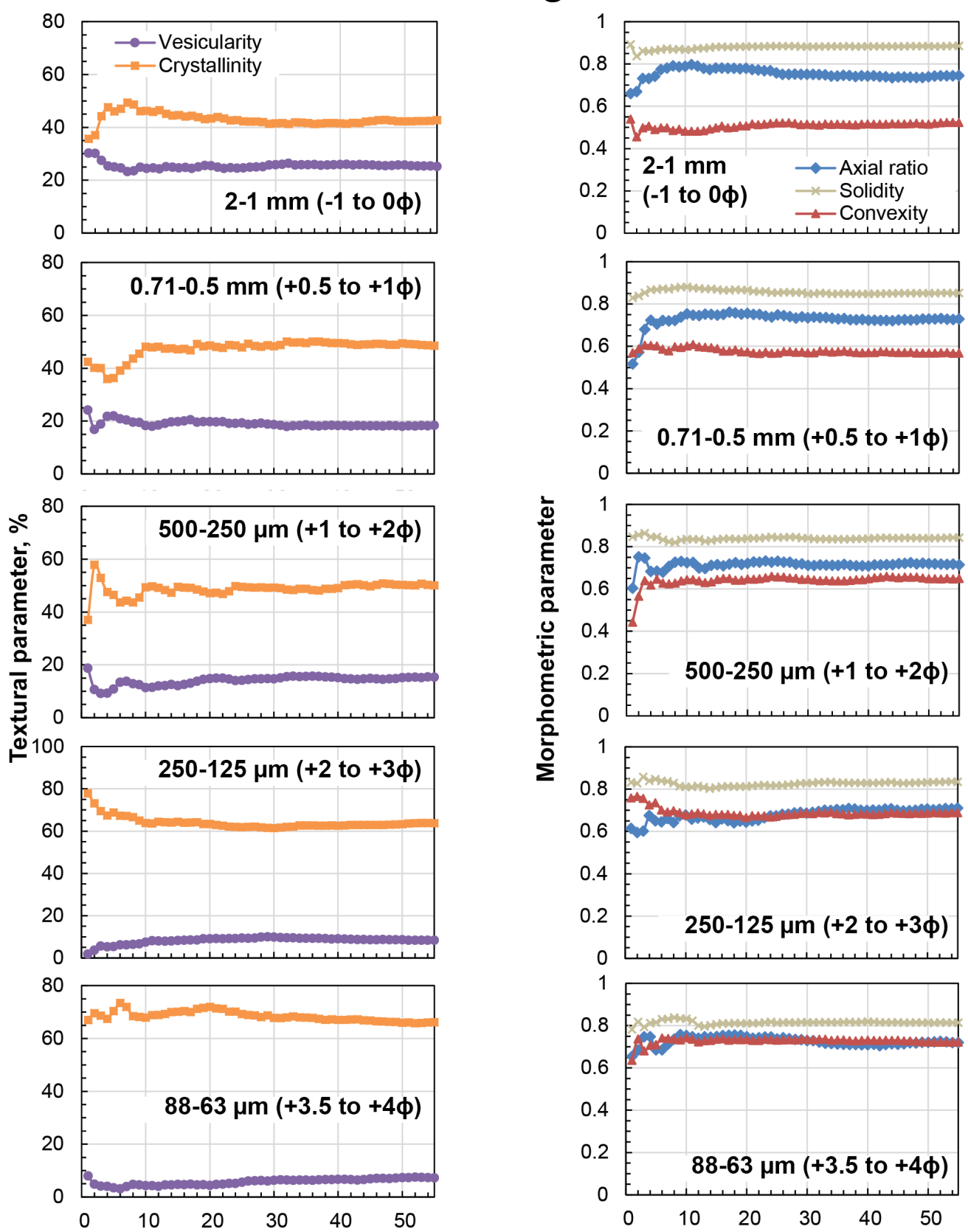

Fig. 10. Stability test to find the optimum number of grains for each size fraction, using the phreatomagmatic sample from Ukinrek. The average values of 2D crystallinity, 2D vesicularity and three morphometric parameters stabilize as more grains are added. 


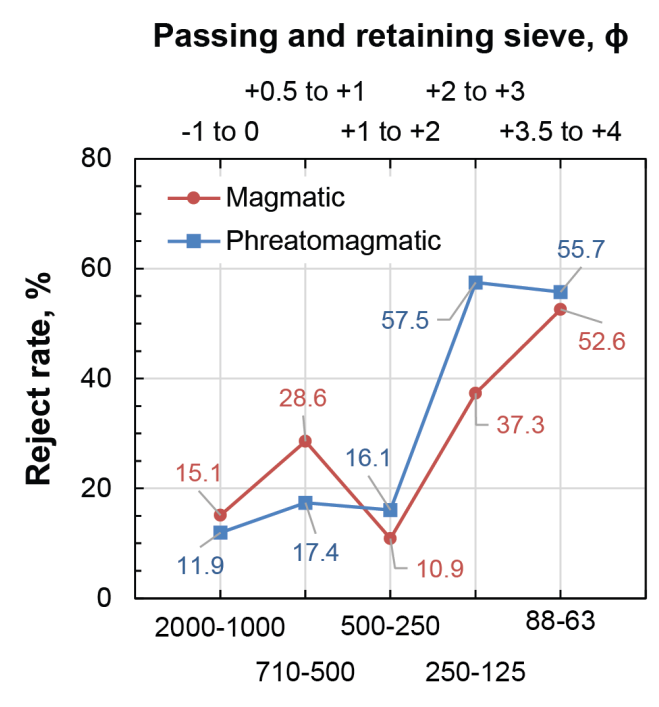

Size fraction, $\mu \mathrm{m}$

Fig. 11. Rejection rate for the Ukinrek examples. Particles are discarded when they are too small, more specifically when their width (the short side of the minimum area bounding rectangle; Dürig et al. 2018) is smaller than the diameter of the holding sieve for the respective size fraction. 

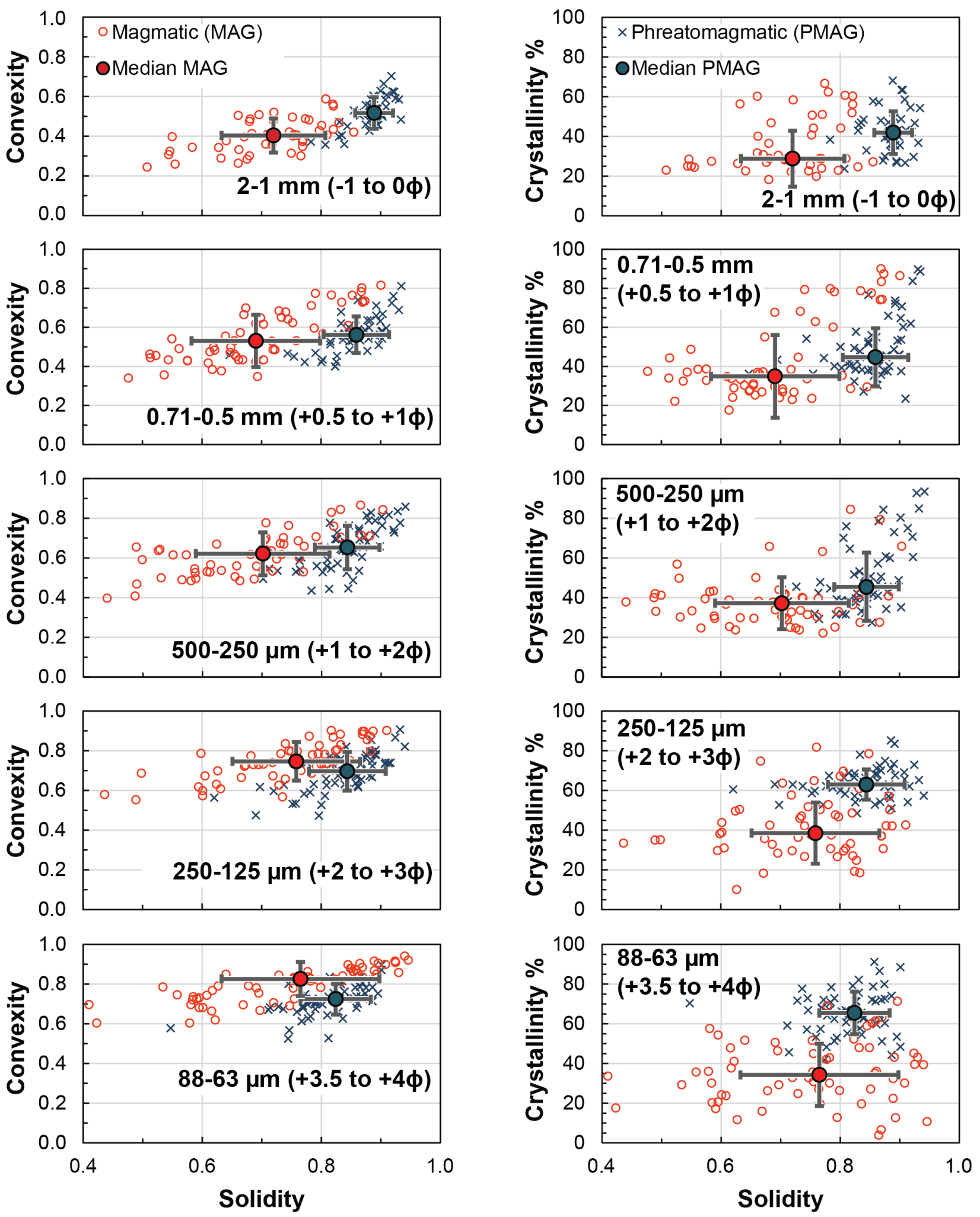

Fig. 12. Convexity and 2D crystallinity versus solidity for both magmatic and phreatomagmatic samples from Ukinrek. The grey error bars represent one standard deviation in each direction. 

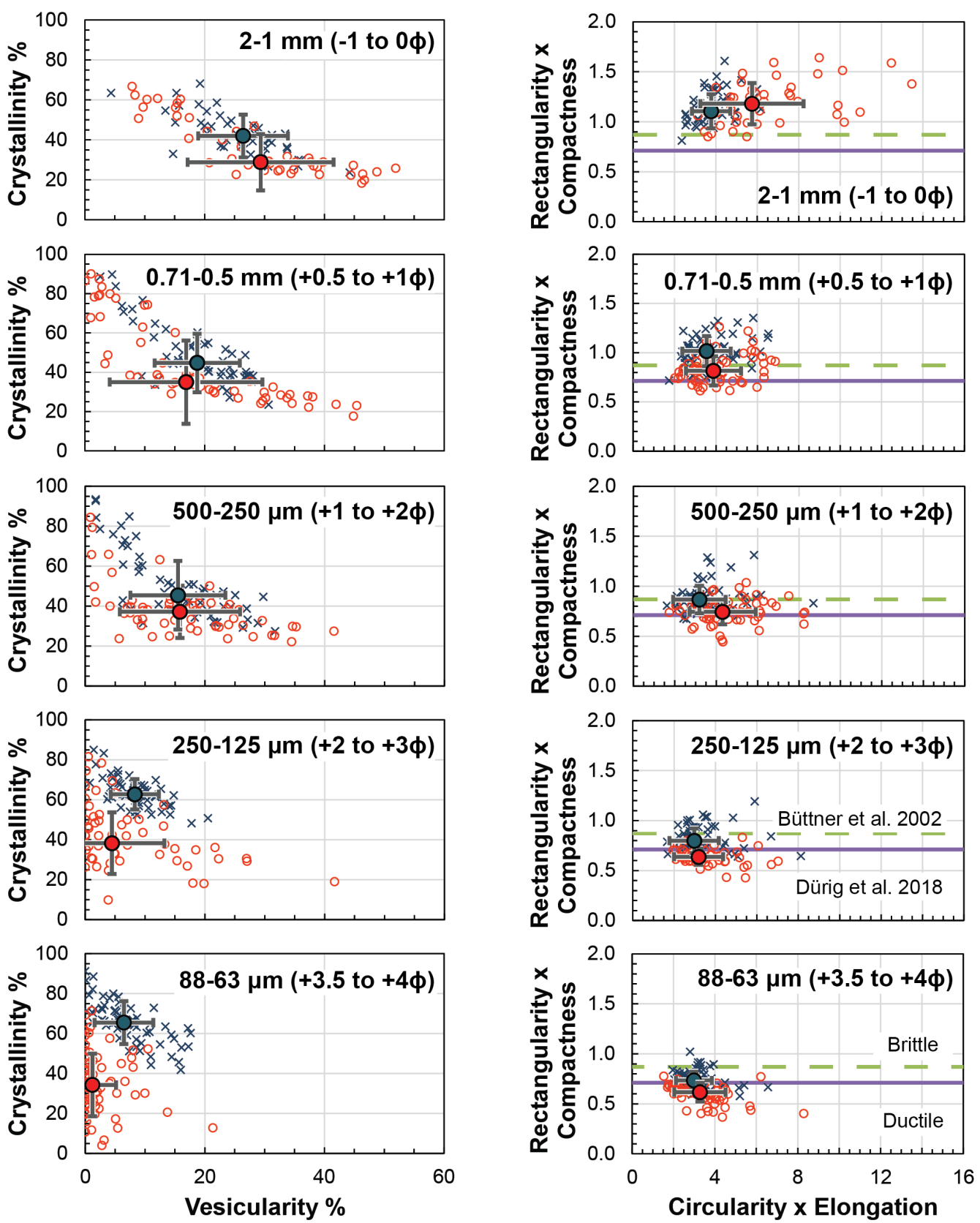

Fig. 13. 2D crystallinity versus 2D vesicularity and the Büttner et al. (2002) plots for both magmatic and phreatomagmatic samples from Ukinrek. The grey error bars represent one standard deviation in each direction. The dashed green line separates ductile from brittle fragmentation for shoshonite clasts smaller than $130 \mu \mathrm{m}$ (Büttner et al. 2002). The solid purple line operates the same distinction for rhyolite clasts smaller than $250 \mu \mathrm{m}$ (Dürig et al. 2018). 


\section{Online resource 1 \\ Making polished epoxy grain mounts of juvenile particles}

This supplementary document describes the manufacturing of polished epoxy grain mounts (PEGMs) of juvenile particles required for the analysis of particle cross-sections. For the sake of completeness, we present instructions for making PEGMs for fractions between $2-1 \mathrm{~mm}$ (- 1 to $0 \phi)$ and $125-63 \mu \mathrm{m}(+3$ to $+4 \phi)$. For simplification, the following instructions assume that the user is mounting clean loose juvenile grains from a specific size fraction. Such a mounting procedure is described as a standard step for the $0.71-0.5 \mathrm{~mm}(+0.5$ to $+1 \phi)$ size fraction in our standardized methodology for studies of primary magma fragmentation (Ross et al. 2021; this study, Fig. 1). For the $88-63 \mu \mathrm{m}(+3.5$ to $+4 \phi)$ fraction, however, a dual mounting procedure is suggested: the user will first manufacture a carbon tape grain mount of the bulk size fraction (see Ross et al. 2021), and then convert it to a PEGM. The instructions presented here can, however, easily be adapted for that procedure as well.

To lighten the text, in the rest of this supplement, size fractions will be designated by the $\phi$ size of the retaining sieve, for example the $2-1 \mathrm{~mm}(-1$ to $0 \phi)$ size fraction will now be called $0 \phi$. We recognize that this creates an ambiguity as to whether " $0 \phi$ " refers to a half- $\phi$ or a full- $\phi$ fraction, but for the purposes of preparing PEGMs, it does not matter: the instructions are the same for a half- $\phi$ or a full- $\phi$ size fraction. Refer to Table 1 in Ross et al. (2021) for a conversion table of $\phi$ to $\mathrm{mm}$.

\section{List of recommended tools/equipment}

Several tools are recommended for the mounting-casting process (Fig. S1), such as: i) wide glass petri dish (Ø 10-15 $\mathrm{cm}$ ); ii) microspatula, spoon and dissecting needle; iii) wood sticks to stir uncured epoxy mixture; iv) ultra-fine point tweezers; v) 1-inch circular plastic ring forms (molds); vi) clear, low viscosity, low shrinkage, epoxy mixture (preferably curing at room temperature); vii) very flat mounting surface (we use a 3.5 inch hard disk drive platter); viii) strong and wide double-sided tape for placing the grains (e.g., carpet tape); ix) ml-range beakers for epoxy handling; x) wax paper; xi) binocular microscope for placing the grains on the sticky mounting surface; xii) cutting mat and art knife, xiii) coarse abrasive sand paper (400-600 GRIT); xiii) very fine permanent marker; xiv) brush.

\footnotetext{
Mounting

Preliminary sample conditions

The sample to be mounted contains only juvenile particles extracted from a discrete size fraction obtained through dry hand sieving, then cleaned in an ultrasonic bath in cycles of 1 minute, for a total of 3 minutes (see Ross et al. 2021). Vacuum impregnation of the grains (to fill vesicles) before
}

mounting is not suitable for this methodology, for several reasons: i) the small particle size of the material would make difficult to preserve the loose state of the particles after impregnation, which is an essential condition for mounting; ii) lack of control on how to deliver the epoxy onto the grains and to extract it once impregnation is completed; iii) increase in time and complexity of the whole PEGM preparation.

\section{Preparation of the mounting support}

Before the sample can be embedded in epoxy, the mold (ring form) and the support need to be appropriately prepared. First, using the sandpaper, polish the ring form on the flat end chosen as the base of the PEGM (to make it very flat and smooth), as well as on the external sides (to make writing easier). Second, for each sample, glue a piece of double-sided tape, significantly larger than the ring form, on the mounting surface (here, the hard drive platter) (Fig. S2a).

Five samples can easily be mounted simultaneously on a hard drive platter. The tape strips should be cut in one go in order to minimize bending and wrinkling of the future mounting surface. With the non-stick covers still present on the upper side, press the tape surfaces with a blunt flat object (avoid fingers as they leave fingerprints) in order to have a tape surface as flat as possible. To trace the mounting area, place the ring form at the center of each tape strip, and mark a circle inside the mold using the permanent marker, which will correspond to the deposition area (Fig. 3a in the paper).

\section{Placement of the grains}

For each sample, lift up the entire non-stick cover by using the art knife and place it temporarily on the cutting mat. There, cut a circle out of the non-stick cover, staying inside the marked line. Place the cover (minus the cut circle) back in position on the tape, pressing all around the rim with the back of the art knife (Fig. S2b).

For size fractions from $0 \phi$ to $+2 \phi$, the juvenile grains are transferred one by one, as follows. Transfer the mounting support inside the large petri dish (Fig. S1). Take the vial containing the juvenile grains and swirl it to homogenize the sample. Using the microspatula, take a small portion of material at a time (about 20 grains) and place it on the nonstick tape cover surrounding the circular area of exposed tape (Fig. $3 \mathrm{~b}$ in the paper). Working under the binocular microscope, pick and drop the grains on the sticky surface, one by one, using the tweezers. Use the needle/probe to orient the particles with the long axes parallel to the mounting surface (Fig. S2c). The goal is to have the grains relatively close together (to require as few SEM images as possible) but clearly separated from each other, with the longest axis parallel to the sticky surface. 


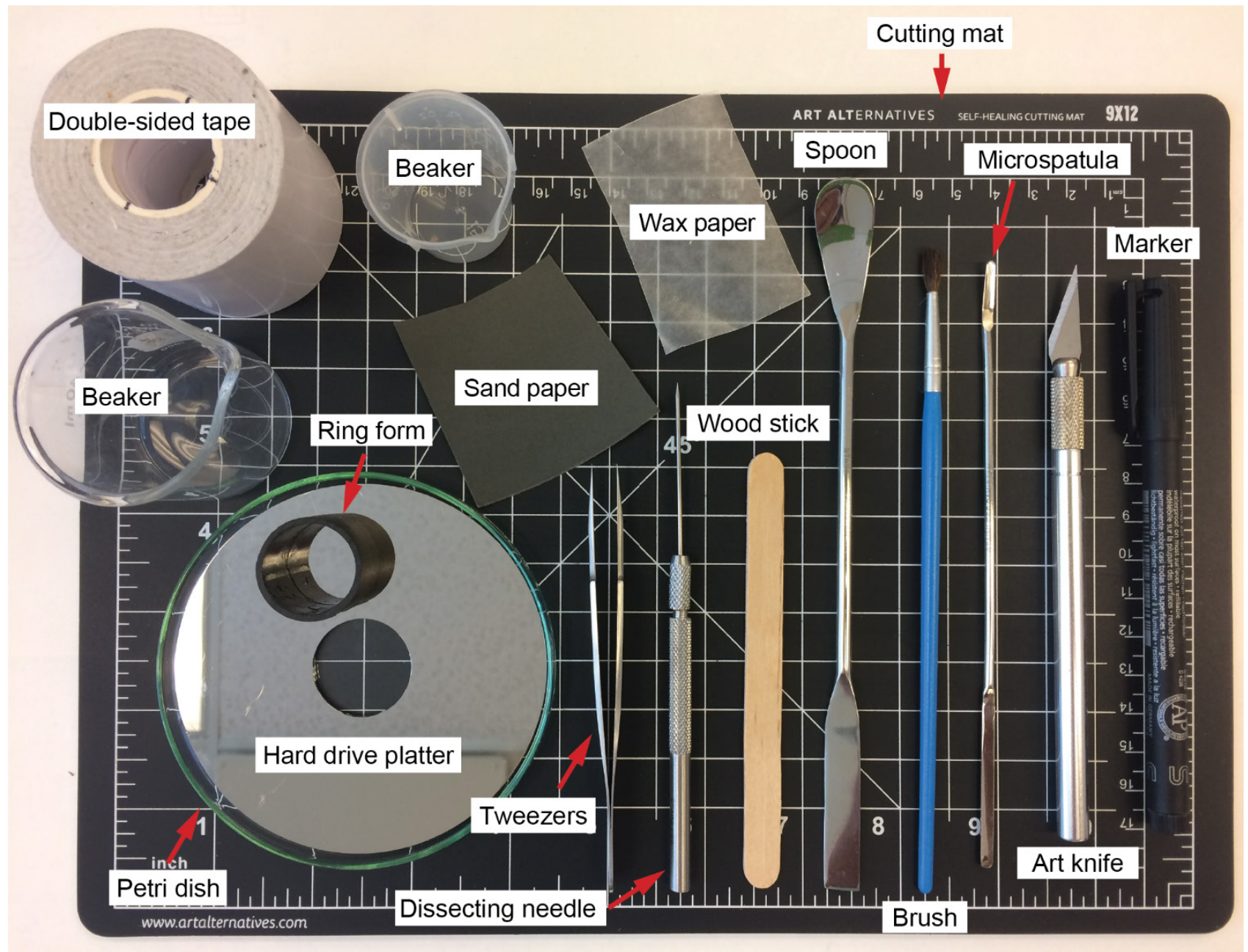

Fig. S1 Illustration of recommended tools for PEGM manufacturing.

For the $+3 \phi$ and $+4 \phi$ size fractions, if mounting large numbers of grains, use the "thumb method" instead:

- Sprinkle a small quantity of juvenile grains on different areas of an empty petri dish. Gently shake the dish sideways in order to displace and separate (as much as possible) the grains, creating a single layer;

- Wet your thumb's fingertip with distilled water, preferably rubbing it on a saturated paper tissue in order to avoid excess water. Very gently rub the moist fingertip over the grains to collect them, then gently transfer the grains on the sticky surface, mimicking the gesture used to take fingerprints (Fig. 3c in the paper);

- Clean the non-stick cover around the circle and other parts of the disk platter from excess particles in order to collect them back for potential future use.

Once grains are mounted, gently remove the holed nonstick cover (exposing the entire tape surface), then firmly place the ring form into position (Fig. S2d). If are you mounting multiple samples at once, cover the top of the ring form in order to avoid cross-contamination. Placing the ring form after each sample is deposited on the tape also prevents cross-contamination.

\section{Epoxy casting and curing}

We successfully tested the EpoThin 2 epoxy castable system from Buehler ${ }^{\mathbb{B}}$. It consists in a very low viscosity $(350 \mathrm{mPa} \cdot \mathrm{s})$, low shrinkage clear epoxy mixture that cures at room temperature. This epoxy system is composed by a resin (R) and a hardener $(\mathrm{H})$, which need to be mixed using a ratio of $2 \mathrm{R}: 1 \mathrm{H}$ by volume (or $100 \mathrm{R}: 45 \mathrm{H}$ by weight). Once mixed, the compound cures within 9 hours producing a hard, clear epoxy polymer, reaching a low peak exotherm up to $40^{\circ} \mathrm{C}$ during the curing process.

To proceed, cover the working area (countertop) with wax paper. For safety, it is recommended to wear gloves and a face mask when handling the epoxy, or work under a ventilation hood. 

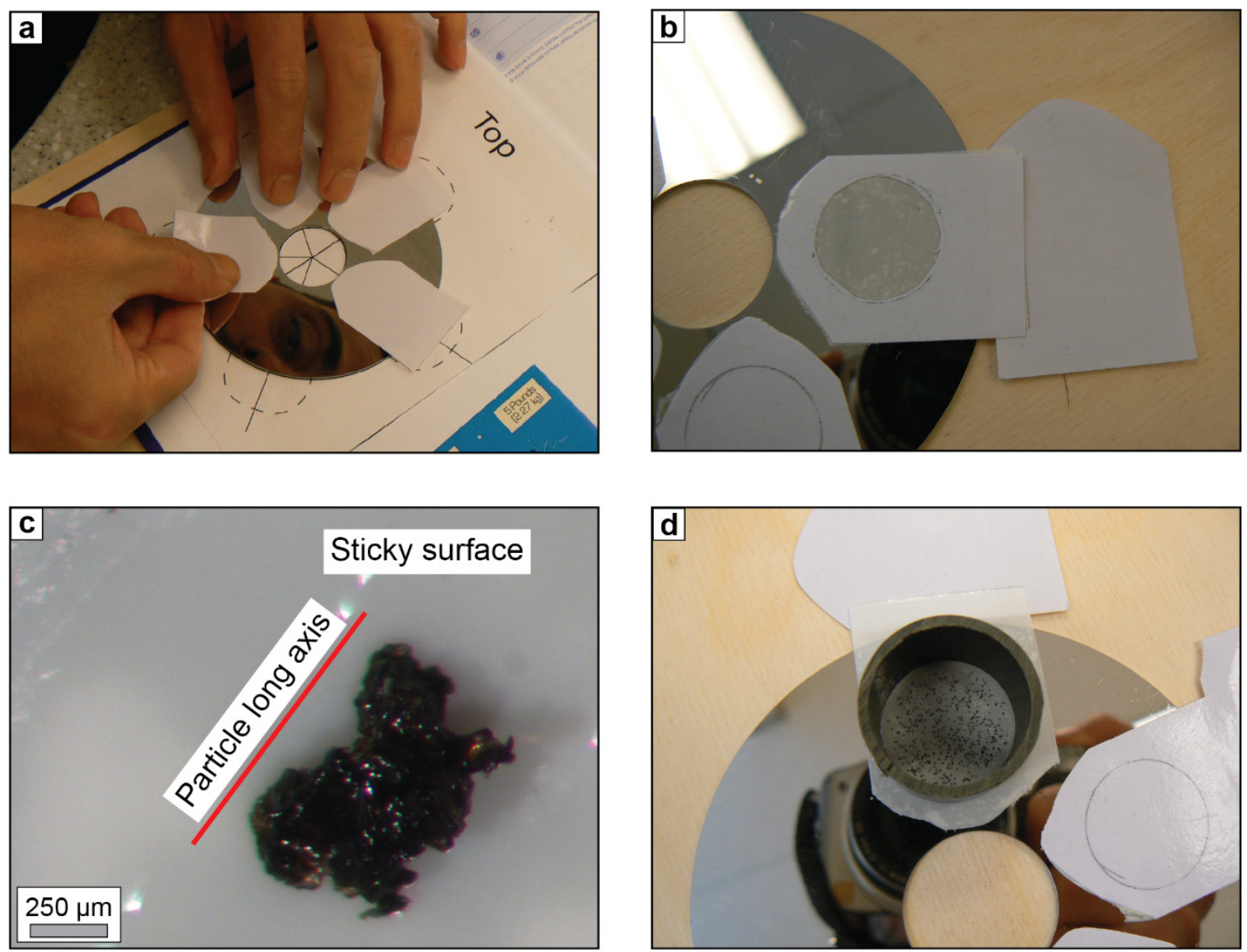

Fig. S2 Mounting the juvenile particles. a) Sticking the double-sided tape on the flat support. b) Sticky area of the tape exposed for particles placement. c) Detail of a grain oriented with the longest axis parallel to the sticky surface (top-down view). d) Ring form placed into position around juvenile particles (black dots), ready for casting.

Use three beakers and stirrers to handle the epoxy resin, hardener and resultant mixture, respectively. Considering the size fractions used in our work $(0 \phi$ to $+4 \phi)$ and the diameter of the ring form, $3 \mathrm{~g}$ of epoxy is optimal for each PEGM ( $\sim 2 \mathrm{~g}$ of resin, $\sim 1 \mathrm{~g}$ of hardener). To prepare the epoxy, place the mixture beaker on the scale, then set the scale to zero. Pour the resin and the hardener consecutively into the beaker in the required quantities considering the number of PEGMs being prepared. Blend the mixture slowly with the stick, keeping it vertical. Slow gentle stirring minimizes air bubbles in the epoxy, negating the need to cure the samples in a vacuum. Strings will appear in the mixture as the resin and hardener have different viscosities. Stir until no strings are visible and the solution appears fairly homogeneous.

Finally, place the mounted samples on the balance, set to zero, then pour $3 \mathrm{~g}$ of the epoxy mixture into each mold (Fig. 3d in the paper). Leave the samples to cure at room temperature and atmospheric pressure overnight (or in a vacuum if air bubbles are visible), and place heavy weights on top of each ring form to avoid epoxy leakage from the base of the ring form. This aspect is crucial, since otherwise the detachment of the ring form will generate a tilted PEGM. This means that the grains will not be exposed at the same level, making the PEGM unsuitable for analysis.

\section{Manual grinding and polishing}

Automated grinding and polishing machines are available in some labs, but here we present a manual method that only requires a simple grinding/polishing machine (Fig. $3 \mathrm{e}$ in the paper). The protocol developed in this work exposes the central portion of the smallest juvenile particles embedded in a PEGM. It consists of up to five steps (3 of grinding, 2 of polishing) using first abrasive papers, then abrasive powderwater mixtures. For $0 \phi$ and $+1 \phi$ size fractions, run steps 1 to 5 ; for $+2 \phi$, start at step 2 ; for $+3 \phi$ and $+4 \phi$, start directly at step 3 (Fig. S3). Each step can be adjusted according to the machinery and conditions available at other institutions. Please refer to table S1 for the complete set of thicknesses to be eroded for each full phi size fraction. 


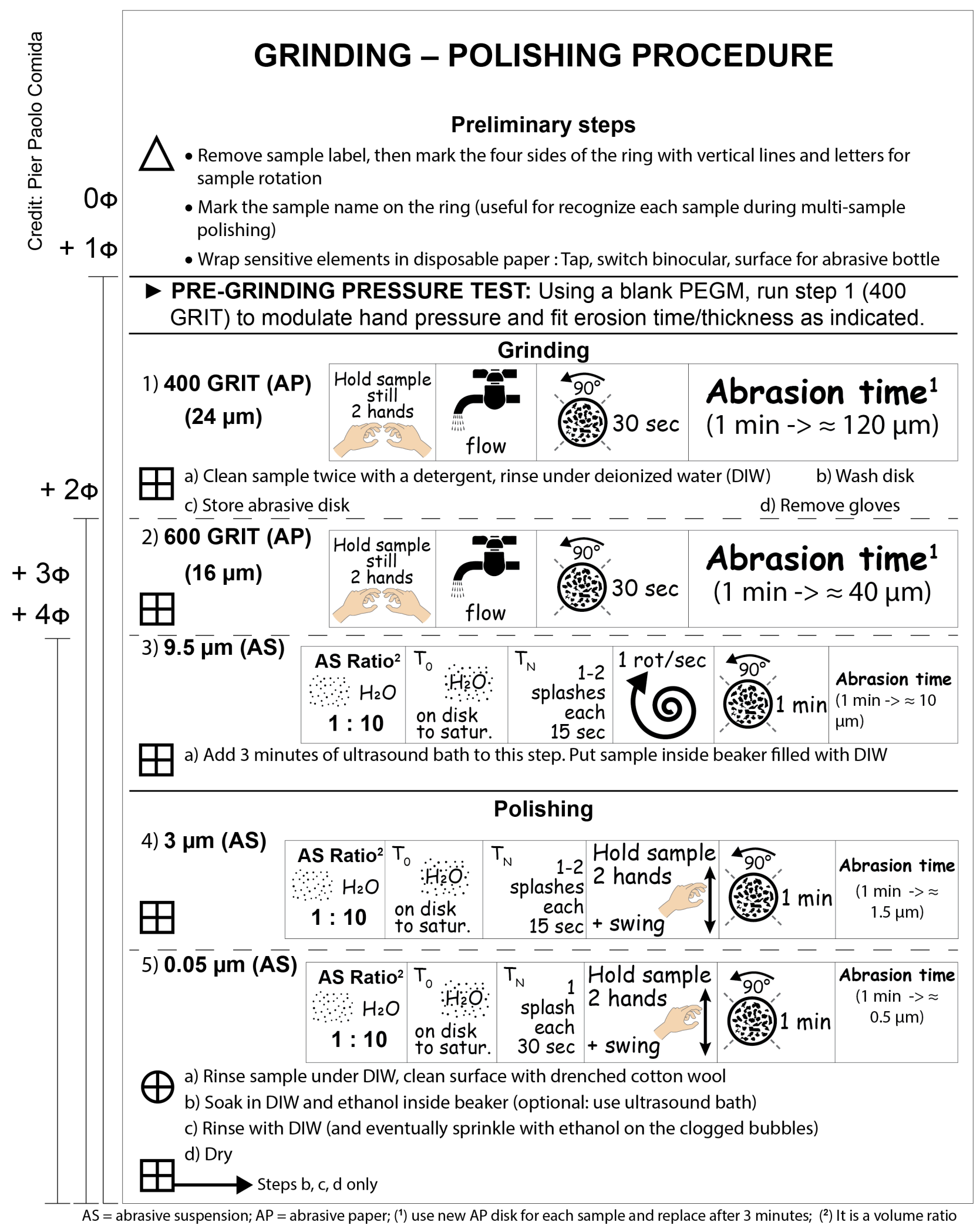

Fig. S3. Printable directions for manual grinding and polishing of PEGMs. 
Table S1 Thickness to erode during grinding/polishing, in order to reach the center of the smallest particle found on each size fraction

\begin{tabular}{|c|c|c|c|c|c|}
\hline \multirow[t]{2}{*}{ Steps } & \multicolumn{5}{|c|}{ Size fraction $\phi(\mu \mathrm{m})$} \\
\hline & $0(2000-1000)$ & $+1(1000-500)^{*}$ & $+2(500-250)$ & $+3(250-125)$ & $+4(125-63)^{*}$ \\
\hline Grinding & \multicolumn{5}{|c|}{ Thickness to erode $(\mu \mathrm{m})$} \\
\hline 1) $24 \mu \mathrm{m}(400 \mathrm{GRIT})$ & 375 & 150 & - & - & - \\
\hline 2) $16 \mu \mathrm{m}(600 \mathrm{GRIT})$ & 100 & 75 & 90 & - & - \\
\hline 3) $9.5 \mu \mathrm{m}$ & 15 & 15 & 25 & 50 & 18 \\
\hline
\end{tabular}

Polishing
4) $3 \mu \mathrm{m}$
5) $0.05 \mu \mathrm{m}$
2

\begin{abstract}
* The instructions are the same whether using full phi sieves (example $+1 \phi=1.0-0.5 \mathrm{~mm}$ ) or half-phi sieves (example, narrow $+1 \phi=0.71-0.5 \mathrm{~mm}$ ) to create size fractions, since the aim is to grind and polish the mount down to the middle of the smallest particle.
\end{abstract}

If using half- $\phi$ size fractions in which the retaining sieve is a whole number, the relevant thicknesses to be removed are the same as for full- $\phi$ fractions: for example, for the +0.5 to $+1 \phi$ fraction $(0.71-0.5 \mathrm{~mm})$, follow the instructions for the full $+1 \phi$ fraction $(1-0.5 \mathrm{~mm})$. I.e., in both cases, we remove a total of $0.25 \mathrm{~mm}$ of mold, resin and particles to expose the center of the smallest grains.

\section{Preliminary step}

If there are any leaked epoxy or indentations, smooth the side of the PEGM surface to be grinded and polished using a coarse $400-600$ grit $(24-16 \mu \mathrm{m}) \mathrm{SiC}$ paper.

\section{Grinding pressure test}

In manual grinding, the pressure exerted on the sample placed on the rotating disk has a major influence on the thickness eroded within a specific amount of time. Applying too much pressure would result, for instance, in the irreversible loss of sample or the generation of fractures within the particles.

To minimize and control this issue, the user should run tests of grinding step 1 (see below) using a blank (juvenile particle-free) PEGM and adjust the hand pressure to fit the rates $(\sim 120 \mu \mathrm{m}$ of abrasion per minute) provided in the printable directions (Fig. S3). Using that specific hand pressure, the abrasion times for each step will be correct.

\section{Grinding steps}

1) $24 \mu \mathrm{m}$ (400 GRIT) $\mathrm{SiC}$ abrasive paper - With the grinder on and water flowing, hold the sample firmly with two hands, and press its surface onto the rotating abrasive paper disk. The sample is not continuously moved during this step, but is rotated counterclockwise by $90^{\circ}$ every 30 seconds, in order to keep the surface horizontal. For the $+1 \phi$ size fraction, remove $\sim 150 \mu \mathrm{m}$ of material (corresponding to a grinding time of $\sim 75$ seconds).

2) $16 \mu \mathrm{m}$ (600 GRIT) SiC abrasive paper - Same directions as step 1 . For $+1 \phi$, remove $\sim 75 \mu \mathrm{m}$ of material (corresponding to a grinding time of $\sim 115$ seconds).

3) $9.5 \mu \mathrm{m} \mathrm{Al}_{2} \mathrm{O}_{3}$ abrasive suspension - To grind with the abrasive suspension, fit the platen with the polishing pad of choice, and saturate it with the abrasive suspension (once the machine is on). Press the sample onto the pad and rotate in the opposite direction relative to the platen, at a pace of about one circle per second, drawing a spiral back and forth toward the center. Turn the sample counterclockwise by $90^{\circ}$ every minute. In order to keep the surface of the platen constantly moistened, pour 1-2 splashes of suspension roughly each 15 seconds. For $+1 \phi$, remove $\sim 15 \mu \mathrm{m}$ of material (corresponding to a grinding time of $\sim 70$ seconds).

After each grinding step, the sample is thoroughly cleaned with a detergent to avoid cross-contamination. At the end of step 3 the sample is additionally cleaned in the ultrasound bath.

\section{Polishing steps}

4) $3 \mu \mathrm{m} \mathrm{Al} \mathrm{Ol}_{2} \mathrm{O}_{3}$ abrasive suspension - Directions are the same as for step 3, but the sample is now shifted back and forth from the center of the platen. For $+1 \phi$, remove $\sim 8 \mu \mathrm{m}$ of material (corresponding to a polishing time of $\sim 320 \mathrm{~s}$ ). 
5) $0.05 \mu \mathrm{m} \mathrm{Al} \mathrm{Al}_{2} \mathrm{O}_{3}$ abrasive suspension - Same directions as step 4, with splashes of suspension added every 30 seconds or less. For $+1 \phi$, remove $\sim 2 \mu \mathrm{m}$ of material (corresponding to a polishing time of $\sim 360 \mathrm{~s}$ ).

The final cleaning of the sample surface involves the use of cotton wool and running water. A very short cycle in the ultrasound bath and ethanol can be used to remove abrasive powder stuck inside open vesicles, if necessary.

\section{References cited}

Ross P-S, Dürig T, Comida PP, Lefebvre NS, White JDL, Andronico D, Thivet S, Eychenne J, Gurioli L (2022) Standardized analysis of juvenile pyroclasts in comparative studies of primary magma fragmentation; 1. Overview and workflow. Bull Volc https://doi.org/10.1007/s00445-02101516-6 


\section{Online resource 2 Measurement data spreadsheets}

To download theExcel spreadsheet with all the morphometric and textural measurement data, see the online version of the article on the journal website, or contact the corresponding author. 


\section{Online resource 3 Axial ratio versus pixel density plots}

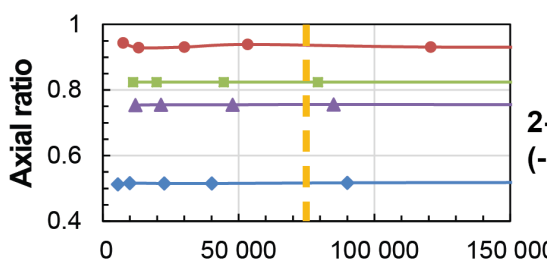

2-1 $\mathrm{mm}$

$(-1$ to $0 \phi)$
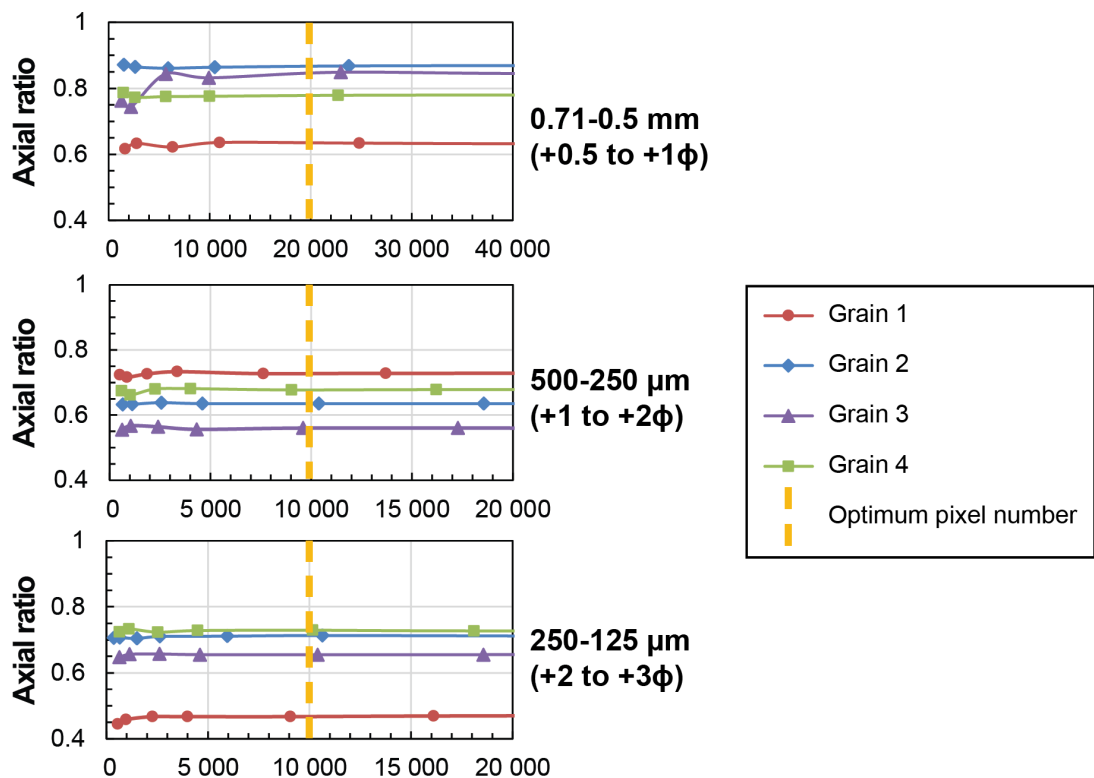

250-125 $\mu \mathrm{m}$

$(+2$ to $+3 \phi)$

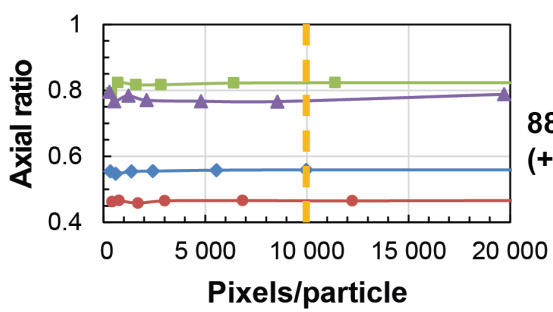

88-63 $\mu \mathrm{m}$

$(+3.5$ to $+4 \phi)$

Pixel number test for axial ratio, using the Ukinrek Strombolian sample. Four grains were tested for each size fraction, covering the highest and lowest axial ratio. Each trend line corresponds, within a single size fraction, to the same grain. The vertical dashed lines indicate the optimum pixel numbers for each size fraction (all parameters considered, see also Figs. 6 and 7 in the main manuscript). 